\title{
On the Use of Surfactant for Precursor Solution Processing and Influence on the Properties of Tin Dioxide Thin Films
}

\section{Lucas P. Fonseca}

UNESP: Universidade Estadual Paulista Julio de Mesquita Filho

Luiz F. K. Pedrini

UNESP: Universidade Estadual Paulista Julio de Mesquita Filho

João V. M. Lima

UNESP: Universidade Estadual Paulista Julio de Mesquita Filho

Lucas C. Escaliante

UNESP: Universidade Estadual Paulista Julio de Mesquita Filho

\section{Stevan B. O. Santos}

UNESP: Universidade Estadual Paulista Julio de Mesquita Filho

\section{Luis Vicente de Andrade Scalvi ( $\square$ luis.scalvi@unesp.br)}

UNESP FC: Universidade Estadual Paulista Julio de Mesquita Filho Faculdade de Ciencias Campus de Bauru https://orcid.org/0000-0001-5762-6424

\section{Research Article}

Keywords: tin dioxide, surfactant, sol-gel, electrical and optical properties

Posted Date: April 3rd, 2021

DOl: https://doi.org/10.21203/rs.3.rs-376927/v1

License: (c) (i) This work is licensed under a Creative Commons Attribution 4.0 International License.

Read Full License 


\title{
On the use of surfactant for precursor solution processing and
}

\section{influence on the properties of tin dioxide thin films}

Lucas P. Fonseca ${ }^{\text {a }}$, Luiz F. K. Pedrini ${ }^{\text {b }}$, João V. M. Lima ${ }^{\text {b }}$, Lucas C. Escaliante ${ }^{\text {b }}$, Stevan B.

O. Santos ${ }^{\mathrm{a}, \mathrm{b}}$, Luis V. A. Scalvi ${ }^{\mathrm{a}, \mathrm{b}(*)}$

a São Paulo State University (Unesp), School of Sciences, Department of Physics, Bauru, SP, 17033360, Brazil

${ }^{b}$ São Paulo State University (Unesp), School of Sciences, POSMAT - Post-Graduate Program in Materials Science and Technology, Bauru, SP, 17033-360, Brazil

(*) corresponding author luis.scalvi@unesp.br

\begin{abstract}
Tin dioxide $\left(\mathrm{SnO}_{2}\right)$ thin films have several sorts of applications, including as gas sensors and in photocatalysis, where the surface area plays a relevant role. The use of the Triton X-100 non-ionic surfactant in the precursor solution processing has revealed as a fundamental aid to increase adhesion of the $\mathrm{SnO}_{2}$ film on the substrate. Moreover, the surfactant presence leads to a significant increase in the surface area of deposited thin films, and the roughness (rms) increases from $57.6 \mathrm{~nm}$ to $275 \mathrm{~nm}$. The influence can also be observed in the XRD profiles, with a higher degree of crystallinity for Triton deposited films. It also increases the defect density and the electron scattering, leading to rather resistive films which are thermally excited only above room temperature. The activation energy for the defect ionization is rather high, $800 \mathrm{meV}$, but the thermal excitation takes place at a lower temperature range, compared to films prepared without Triton in the solution processing. The performance on photocatalysis is improved for films prepared with Triton X-100, since most of the methylene blue dye is degraded in the first 90 minutes when interacting with the sample.
\end{abstract}

Keywords: tin dioxide, surfactant, sol-gel, electrical and optical properties 


\section{Introduction}

Tin dioxide $\left(\mathrm{SnO}_{2}\right)$ has received increasing interest for use in several sorts of applications, ranging from gas sensors, catalysts, transparent optoelectronic devices to solar cells [1]. One of its interesting properties is its high transparency in the visible range of the electromagnetic spectrum, which combined with a tunable electrical conductivity makes it particularly attractive for application in optoelectronic devices. This conductivity depends on the deposition method, and may be rather high even without doping [2], taking into account that $\mathrm{SnO}_{2}$ is a naturally n-type semiconductor oxide, occurring due to the presence of punctual defects in its lattice, such as oxygen vacancies and interstitial tin atoms, which act as donors in $\mathrm{SnO}_{2}$ [3]. As a consequence of these intrinsic donor levels, the electron density is rather high [4] being the conductivity modulated by the electron mobility.

The sol-gel dip-coating technique has been chosen in this paper to deposit samples (films), for being quite simple, inexpensive and with possibility of coating large areas $[5,6]$. It leads to films with interesting characteristics, such as larger contact surfaces and greater porosity compared to other deposition methods [7]. On the other hand, some properties arising from this deposition technique may not be efficient in relation to the requested applications, such as the adhesion of the thin film on the desired substrate, thus, the use of a surfactant in the colloidal suspension may improve this condition.

The introduction of surfactants to the synthesis of films and nanoparticles has been used recently, either as a capping and stabilizing agent, or as a controlling mechanism to manipulate the size of crystallites. Afzal et al. [8] developed a $\mathrm{SnO}_{2}$-surfactant composite film through pyrolysis that resulted in higher sensitivity for gas-sensing properties for compositions containing 4\% of Triton X-100 and a smaller particle size for highly doped $\mathrm{SnO}_{2}$ films. Bhattacharjee and coworkers [9] adds triton X-100 to the synthesis process also as a capping agent and for manipulating the formation and size of nanoparticles, besides comparing the results with a cationic surfactant (CPC). Rac et al. [10] shows that the interrelationship between the precursor solution's $\mathrm{pH}$ and the stability of complex structures $\left(\mathrm{SnO}_{2}\right.$ agglomerates) and complex molecules (polymers) correlates with the properties of resulting nanoparticles. From these relationships between the synthesis path and obtained nanoparticle's properties we may try to establish parallels between thin-film samples and applications for photocatalysis. Tin dioxide has been reportedly efficient with regard to photocatalytic properties [11], moreover, the coupling of $\mathrm{SnO}_{2}$ with other semiconductor 
oxides such as $\mathrm{TiO}_{2}, \mathrm{ZnO}$ and $\alpha-\mathrm{Fe}_{2} \mathrm{O}_{3}$ has originated heterostructures with improvements in the electron-hole recombination rate, as well as compatible crystallographic directions [1214]

In this work, direct application of the surfactant Triton X-100 leads to improvement of adhesion of thin films through homogenization of deposition by the formation of micelles, which prevents particle agglomeration and promotes the distribution of metallic Sn particles throughout the colloid, and the homogenization of morphology [15-17]. In addition, the influence of this nonionic organic compound on electrical, optical, structural and morphological characteristics of deposited thin films of $\mathrm{SnO}_{2}$ is analyzed, aiming for the obtainment of thin films with larger contact surface area and higher porosity, which are interesting characteristics for application in photocatalytic devices and gas sensors [18]. It is observed that the addition of the chosen surfactant affected the samples in different ways: better adhesion and homogeneity of the deposited film on different substrates, increased roughness and increased pore volume.

The Triton X-100 molecule is represented in figure 1, where the division between hydrophilic and hydrophobic parts is also shown.

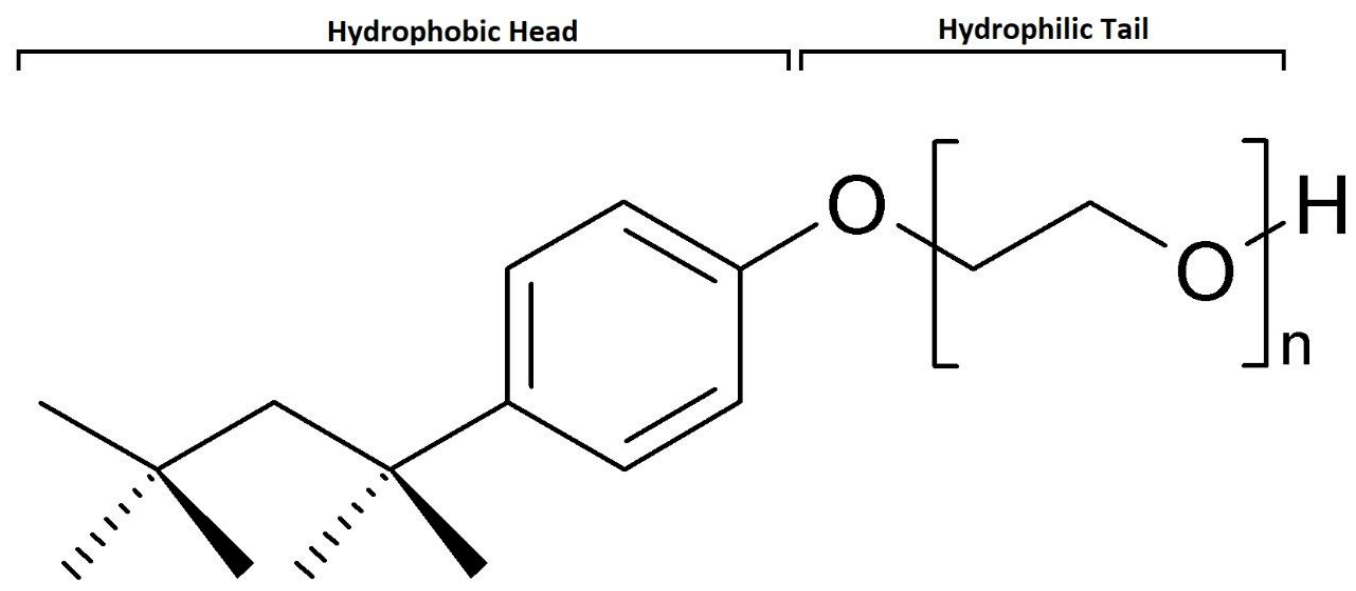

Figure 1: Triton $\mathrm{X}-100$ molecule $\left(\mathrm{C}_{14} \mathrm{H}_{22} \mathrm{O}\left(\mathrm{C}_{2} \mathrm{H}_{4} \mathrm{O}\right)_{\mathrm{n}}\right)$, where $n$ is between 9 or 10 unities.

The improvement in adhesion observed with the addition of this surfactant as a reagent in the colloidal suspension is a result of different interactions. While still in the precursor solution, with films not yet deposited, the surfactant leads to stability and aggregation of particles through the formation of micelles, thus acting as dispersants and stabilizers in the solution. Through this dispersing behavior, the surfactant prevents the 
formation of particles above a critical volume, avoiding precipitation and maintaining homogeneity in the solution, thus, helping in the homogeneity of the prepared sample. When deposited, the surfactant assists in the interaction of the film with the substrate, establishing connections with the substrate regardless of hydrophilic or hydrophobic characteristics, varying only the binding mechanism. In the first case, the extensive polymer chain binds to the surface, in the second case the aromatics and non-polar chains bind and keep the chains apart [19]. These configurations maximize contact area between hydrophilic regions while minimizing contact areas between hydrophobic regions with the aqueous solution. As the deposition proceeds, drainage removes part of the solvents and increases the interaction surface among the deposited polymer, the substrate and the particles of the material being deposited. The used substrate (soda-lime glass) is hydrophilic (wetting angle about $15^{\circ}[20]$ ), with a larger surface area generated by the structure formed by the polymer, in conjunction with the solution viscosity and the interaction between solution and substrate, which also becomes higher. The overall result is a better adhesion and greater possibility of branching and growth of the deposited material.

\section{Experimental}

\subsection{Sample preparation}

The substrates used for thin film deposition were soda-lime glass and silica, the second being used only to determine $\mathrm{SnO}_{2}$ bandgap, since soda-lime glass and tin dioxide have the fundamental absorption edge in the same range, what could mask a more precise determination. A solution of $30 \%$ volume of Extran neutral detergent and $70 \%$ of deionized water was used for substrate cleaning, being kept for $20 \mathrm{~min}$. in a USC-1800 ultrasonic cleaner. After being removed from this solution, substrates were washed with deionized water, acetone and isopropyl alcohol, consecutively, and dried using a Black and Decker HG2000-B2 thermal blower. Precursor solutions of $\mathrm{SnO}_{2}$ were prepared in aqueous media $(0.5 \mathrm{~mol} / \mathrm{L})$, obtained by dissolving tin tetrachloride pentahydrate $\left(\mathrm{SnCl}_{4} .5 \mathrm{H}_{2} \mathrm{O}\right)$. Hydrolysis of $\mathrm{Sn}^{4+}$ ion was accelerated by addition of ammonium hydroxide $\left(\mathrm{NH}_{4} \mathrm{OH}\right)$ under constant magnetic stirring until reaching $\mathrm{pH}$ 11. Then, the resulting volume is separated into semipermeable cellulose membranes that are submerged in deionized water so that hydrolysis takes place and leading to $\mathrm{Cl}^{-}$ion ejection from the solution. The water is kept in circulation to maintain the hydrolysis process over approximately two weeks. After this period, the $\mathrm{pH}$ 
is about 7, and the contents of the membrane bags are transferred to a beaker, for evaporation of part of the solvent and increase in viscosity, and subsequent film deposition [21].

$\mathrm{SnO}_{2}$ thin films were prepared from two colloidal suspensions with $0.27 \mathrm{M}$ of $\mathrm{SnO}_{2}$, however $1 \%$ of the volume of Triton X-100 surfactant was added to one of them. The technique used for thin films deposition was dip-coating, using a controlled speed of 10 $\mathrm{cm} / \mathrm{min}$. For each prepared sample, 10 layers of film were deposited, with heating between each immersion at $250^{\circ} \mathrm{C}$ by $10 \mathrm{~min}$ at room atmosphere, in order to obtain a better layer compacting, resulting in more dense thin films. Samples were submitted to a final thermal annealing at $450{ }^{\circ} \mathrm{C}$ by $1 \mathrm{~h}$, using an oven, with heating rate of $1{ }^{\circ} \mathrm{C} / \mathrm{min}$.

In order to allow electrical characterization of the samples, metallic indium (In) contacts were deposited in a parallel configuration on the $\mathrm{SnO}_{2}$ film surface, through resistive evaporation technique. The metallic contacts have a thickness of $150 \mathrm{~nm}$, determined from a quartz sensor coupled to the evaporation system. The schematic diagram of the final sample architecture is shown in Fig. 2.

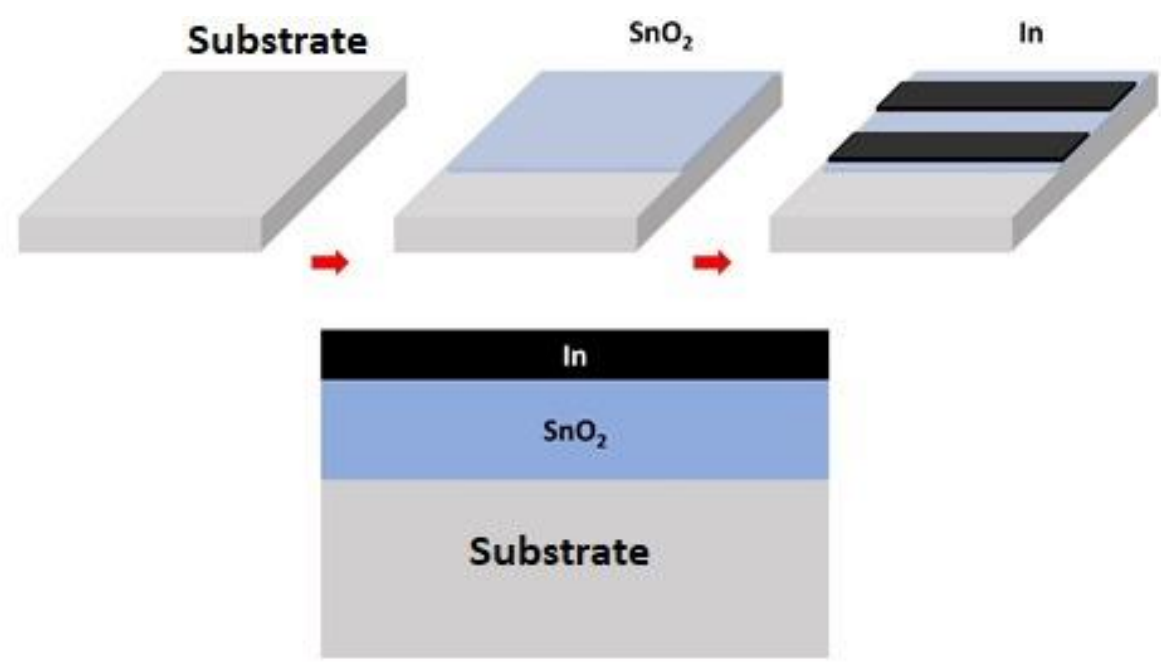

Figure 2: Diagram of $\mathrm{SnO}_{2}$ samples used in this work. Thin film deposited by sol-gel dip-coating, and metallic In contact deposited by resistive evaporation technique.

The samples resulting from this overall procedure are summarized in table 1, where the dimensions of tin dioxide layers are listed. The film thickness is obtained by the following procedure: a kapton tape was placed at the upper end of the substrate so that film was not deposited in this region, thus, with the step formed between the region with and without film, it was possible to estimate the sample thickness by means of a morphological analysis using confocal microscopy. Beside the thickness, table 1 lists the electrical contact width and 
distance between contacts. $S_{W T}$ means colloidal suspension with surfactant Triton X-100, and $S_{W O T}$ without the presence of it during processing.

Table 1: $\mathrm{SnO}_{2}$ samples: film dimensions

\begin{tabular}{cccc}
\hline Sample & $\begin{array}{c}\text { distance } \\
\text { between } \\
\text { contacts }(\mathbf{m m})\end{array}$ & $\begin{array}{c}\text { contact width } \\
(\mathbf{c m})\end{array}$ & $\begin{array}{c}\text { Film thickness } \\
(\mathbf{n m})\end{array}$ \\
\hline$S_{W O T}$ & 3 & $1.3 \mathrm{~cm}$ & 120 \\
$S_{W T}$ & 3 & $1.3 \mathrm{~cm}$ & 420 \\
\hline
\end{tabular}

Samples were also analyzed in form of powder. In this case, all solvent from the tin dioxide suspension was evaporated. Thus, after smashing the resulting crystals, followed by thermal annealing, powders with and without the surfactant in the precursor solution were obtained, as shown in table 2.

Table 2: Definition and thermal annealing temperature of $\mathrm{SnO}_{2}$ powders

\begin{tabular}{cccc|ccc}
\hline & With & Surfactant & & Without & Surfactant & \\
Sample & $S_{\text {WT450 }}$ & $S_{\text {WT550 }}$ & $S_{\text {WT1000 }}$ & $S_{\text {WOT450 }}$ & $S_{\text {WOT550 }}$ & $S_{\text {WOT1000 }}$ \\
$\begin{array}{c}\text { Thermal annealing } \\
\left.\text { temperature ( }{ }^{\circ} \mathrm{C}\right)\end{array}$ & 450 & 550 & 1000 & 450 & 550 & 1000 \\
\hline
\end{tabular}

\subsection{Sample characterization}

To analyze the surface homogeneity and roughness, as well as the presence of pores, the samples surfaces were analyzed through confocal microscopy, using the Leica DCM 3D equipment, equipped with high power white (emission centered at $530 \mathrm{~nm}$ ) and blue LED (460 nm). X-ray diffraction measurements were carried out on a Rigaku D/MAX-2100 / PC 
diffractometer, using $\mathrm{Cu} \mathrm{K \alpha}$ radiation (1.5405 $\AA$ ), and equipped with a Ni filter to attenuate the $\mathrm{K} \beta$ radiation. The used scanning rate was $1^{\circ} / \mathrm{min}$, in the thin film configuration $(2 \theta)$ with an incidence angle of $1.5^{\circ}$, and in the powder configuration $(2 \theta / \theta)$. From the obtained diffractograms, the average crystallite size $(t)$ was obtained from the Scherrer equation [22], $t=k \cdot \lambda /(B \cdot \cos \theta)$, where $\theta$ is the Bragg angle resulting in constructive interference, $B$ is the width of the diffraction peak measured at half of its maximum intensity (in radians), $K$ is a proportionality constant that depends on the geometry of the particles (in this case, it was used 0.9 , considering that crystallites have a spherical shape) and $\lambda$ is the wavelength of the incident X-rays (1.5405 $\AA$, CuKa radiation).

Transmittance and optical reflectance measurements were performed using a Perkin Elmer spectrometer, model Lambda $1050 \mathrm{Uv} / \mathrm{Vis} / \mathrm{Nir}$. The measurements were performed in the range of $1800-250 \mathrm{~nm}$ (scanning in the direction of increasing energy), using an integrating sphere. With the transmittance, it was possible to evaluate the optical bandgap using the Tauc plot [23]. Although the $\mathrm{SnO}_{2}$ band structure is rather complex, and there is a great controversy on the nature of its bandgap transition concerning direct [24,25] or indirect [26,27] nature, our best results are obtained considering indirect transition [28], where the square root of optical absorption coefficient $\left(\alpha^{1 / 2}\right)$ is plotted against the energy $(h v)$.

The optical absorption coefficient may be obtained from [29]:

$$
\alpha=\frac{1}{d} \ln \left[\frac{(1-R)^{2}}{2 T}+\sqrt{\frac{(1-R)^{4}}{2 T^{2}}+R^{2}}\right]
$$

where $\mathrm{R}$ is the reflectance, $\mathrm{T}$ is the transmittance and $\mathrm{d}$ is the film thickness.

When the absorption coefficient is well determined, it is also possible to estimate the Urbach tail width for the samples. The analysis is carried out near the fundamental absorption edge, where the absorption coefficient can be approximated by equation 2 . This tail generally appears in highly degenerate, low-crystalline or amorphous materials, due to localized states that extend inside the bandgap (intra-bandgap states). When obtaining the Urbach energy, it is possible to estimate the material disorder, concerning defects near the conduction band (for p-type semiconductors) or the valence band (for n-type semiconductors). Urbach's energy can be determined by [30]: 


$$
\alpha=\alpha_{0} e^{\left(h v / E_{e}\right)}
$$

where $\alpha_{0}$ is a constant and $E_{e}$ is the width of the Urbach tail. Higher values of $E_{e}$ indicate lower crystallinity and higher disorder in nanomaterials.

Electrical characterization of the films was done through measurements of electrical current as function of the applied voltage and temperature. Measuring current for a varying potential as function of temperature, and using the sample dimensions (distance between contacts and width, film thickness) the resistivity can be evaluated. The biasing and collecting of electrical current was performed with the aid of Keithley electrometers models 2400-c and 6517A. Current measurements as a function of temperature were also performed on samples in a cryostat of APD Cryogenics, operating between 200 and 420K, connected to a temperature controller from Lake Shore Cryotronics model A330 that controls temperature within 0.05 degree of precision. A compressor is also coupled to the system, forming a $\mathrm{He}$ gas closed cycle, using cold water for cooling.

\subsection{Application to Photocatalysis}

The use of the surfactant Triton $\mathrm{X}-100$ in the colloidal suspension leads to modifications on the surface structural and morphological characteristics, such as the surface area of thin films. To take advantage of that, photocatalysis measurements were performed taking into account that similar studies on titanium dioxide $\left(\mathrm{TiO}_{2}\right)$ showed a direct relation of photosensitivity and surface area of thin films [31,32]. For this goal, methylene blue (MB) was used as photocatalysis agent, being a dye with a well-known absorption spectrum, commonly used in the investigation of the photocatalytic properties of a material [33]. For use in the photocatalysis experiments in this work, $\mathrm{MB}$ is diluted in a volume of water and then the sample is dipped. While submerged, the sample is irradiated with ultraviolet light. The maximum of methylene blue absorption spectrum is found about $670 \mathrm{~nm}$, whereas the ultraviolet irradiation generally occurs below $350 \mathrm{~nm}$ [34]. In the present work an Osram mercury lamp (11 W) was used, with emission peak at $254 \mathrm{~nm}$.

The photocatalysis measurements were performed on samples that were submerged in the solution of water and MB for two hours, for adsorption of MB molecules on its surface. After these two hours had elapsed, an aliquot of the solution was removed to determine the 
basis (for each sample) from which the photocatalysis process could be observed. After this first measurement, ultraviolet light was directed to the sample surface still submerged for 90 min and new measurements of transmittance in volumes removed from the solution were performed. This is repeated one last time after 180 minutes of sample irradiation. These aliquots of $\mathrm{MB}$ were analyzed through optical transmittance spectra once more.

\section{Results and Discussion}

\subsection{Structural and morphological properties}

Confocal microscopy images for films with and without the addition of the surfactant Triton X-100 are shown in Fig. 3. Images shown in fig. 3(a) and (b) allows observing that when the film was deposited without the addition of the surfactant in the solution, it results in weaker bond to the substrate, leading to the formation of film islands in some regions. When Triton X-100 was added, a stronger adhesion was observed, and the presence of a $\mathrm{SnO}_{2}$ thin film was observed throughout the substrate, as seen in Fig. 3 (c) and (d). In addition, with the addition of Triton, there was an increase in the root mean squared roughness (rms) of the sample, going from $58 \mathrm{~nm}$ to $275 \mathrm{~nm}$ in the case of surfactant addition to the solution, which can mean a considerable increase in the amount of pores present in the thin film, converging to a much larger surface area. 

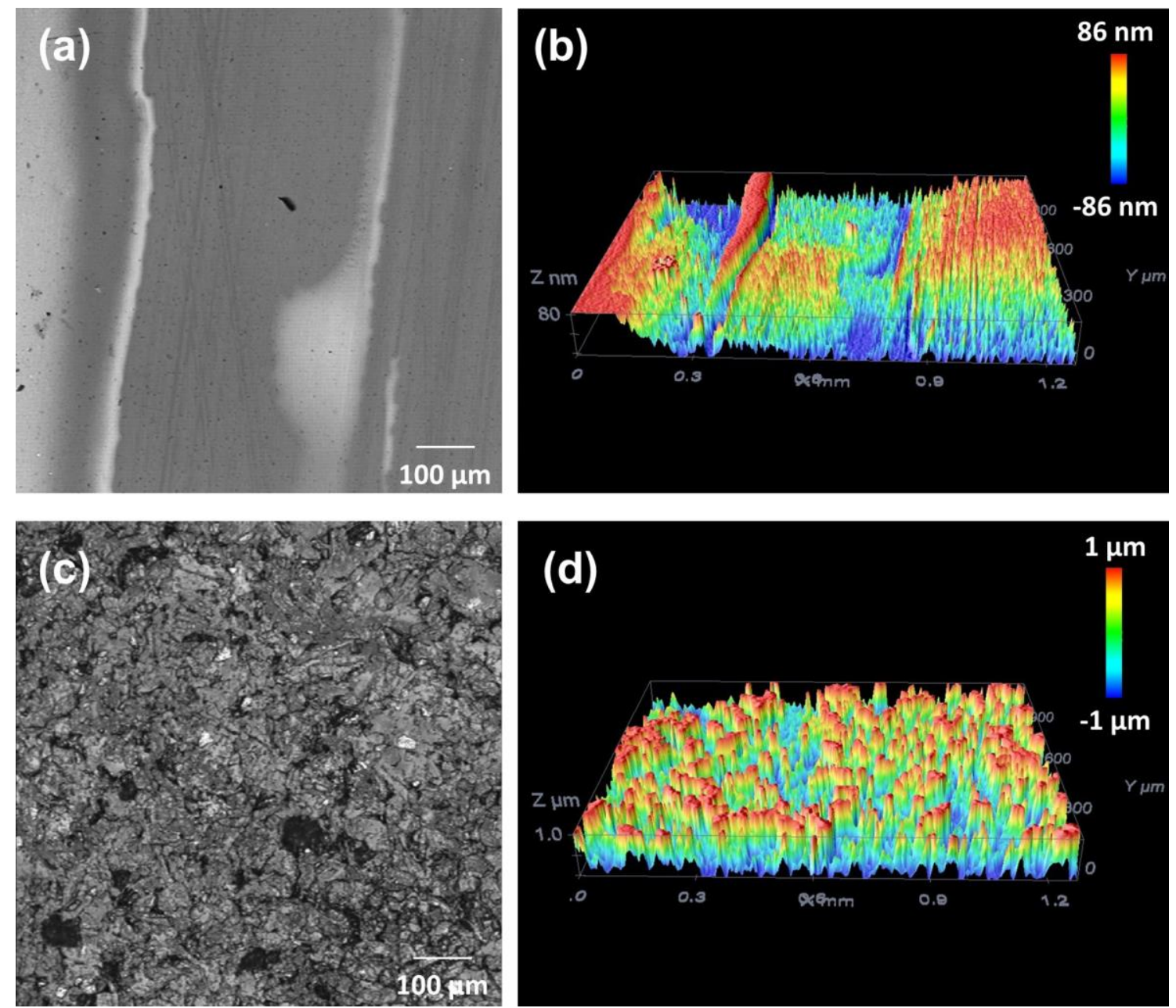

Figure 3: Confocal microscopy images of $\mathrm{SnO}_{2}$ films without Triton in (a) surface and (b) topography mode. Confocal microscopy images of $\mathrm{SnO}_{2}$ samples with Triton in (c) surface and (d) topography mode.

When using surfactant, thermal annealing removes the solvent still left in the sample as well as the surfactant and organic groups from the sample. To accomplish that, the treatments are carried out in air, that is, in an atmosphere containing oxygen. The surfactant degradation and evaporation processes occur gradually and are aided by the oxidation of C$\mathrm{O}-\mathrm{C}$ bonds, from which the monomers chain that are part of the hydrophilic part breaks, forming $\mathrm{C}=\mathrm{O}$ bonds and $-\mathrm{COOH}$ groups $[35,36]$. This separation and the subsequent oxidation of the monomers to their removal from the films during intermediate treatments (between layers) leaves only the hydrophobic part of the polymer behind, which is only removed during final thermal annealing, when sufficient energy becomes available to break the molecules. The products of this reaction are removed from the sample during crystallization, which would be the cause of the formation of pores observed in the final film. As the loss of adhesion of the film on the substrate is not observed, it is possible to consider that, with the gradual elimination of more volatile components (organic surfactant and 
solvent), the particles find lower energy sites, becoming more stable when bonded to the substrate.

Scanning electron microscopy (SEM) measurements were performed on both sorts of samples, which had been previously analyzed through confocal microscopy, aiming at a better understanding of the sample morphology related to the addition of the surfactant to the $\mathrm{SnO}_{2}$ precursor solution. This SEM images are shown in figure 4, without the presence of the surfactant and containing Triton X-100, respectively.
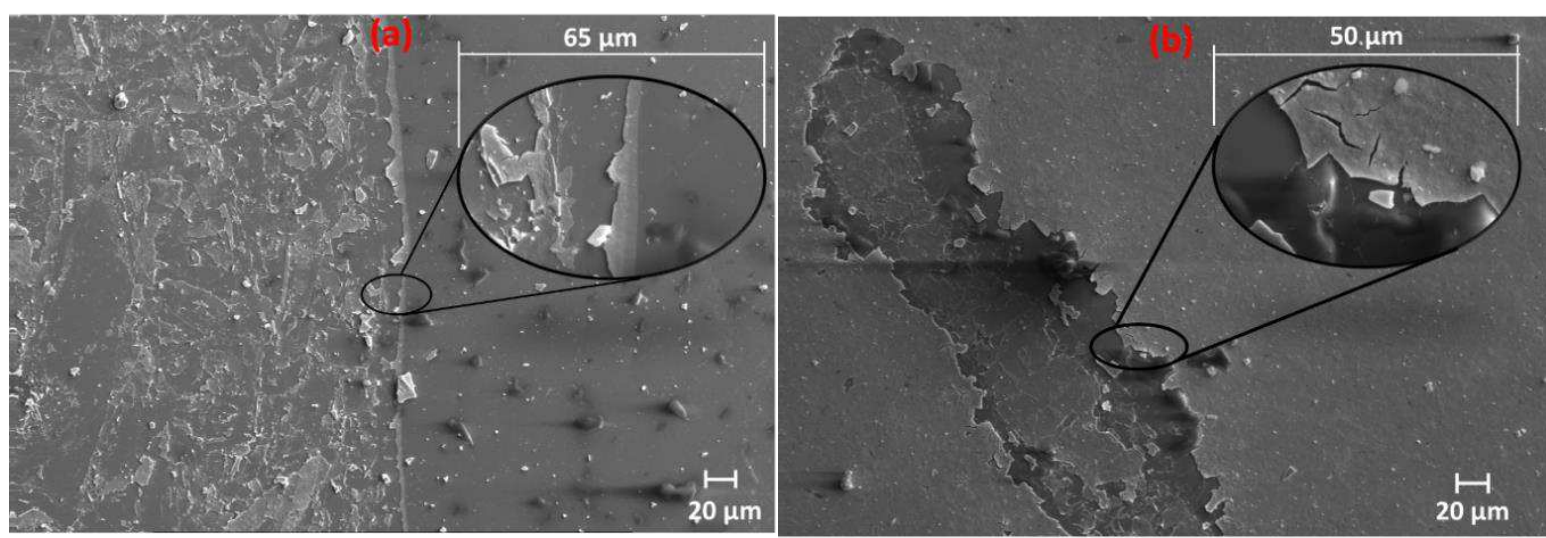

Figure 4: Scanning electron microscopy carried out with magnification 30x and scale bar of $20 \mu \mathrm{m}$ for (a) Swot film (without Triton) and (b) $S_{W T}$. The insets are amplification of the highlighted region in a different magnification for better visualization.

Figure 4 shows SEM images from samples Swot and Swt (without and with Triton respectively). In both images ( $a$ and $b$ ), there is an amplification as an inset of highlighted areas. It is possible to observe in the Swot film (fig. 4(a)) that the formation of $\mathrm{SnO}_{2}$ occurs only through dispersed regions along the substrate, so that relatively large sections of substrate have no coating. Fig. 4(b), where the image acquired from the Swt sample shows, in the same magnitude, the existence of a rough (albeit homogeneous) $\mathrm{SnO}_{2}$ film that seems to cover most of the substrate. These results are in good agreement with confocal microscopy topographies seen in figure 3.

The composition of the material formed in different regions of the samples, with and without the presence of surfactant in the precursor solution, was analyzed through measurements of energy dispersive spectroscopy (EDS) and the results are shown in figures 5 and 6 , along with the amplification of the insets of fig. 4, which are reproduced for better understanding of differences on morphology of films produced by both procedures. 

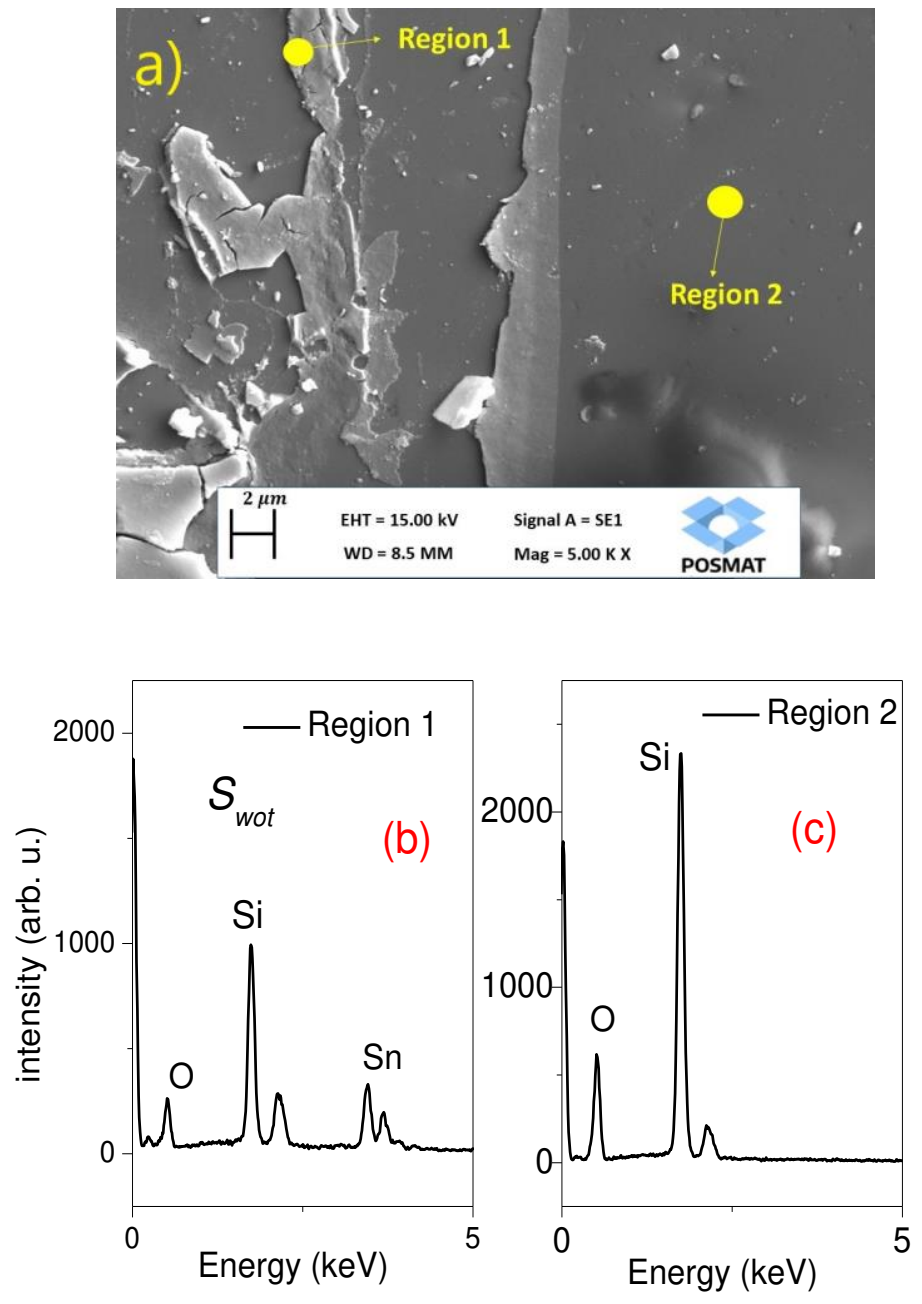

Figure 5: SEM and energy dispersive spectroscopy (EDS) of sample $\mathrm{S}_{\mathrm{WOT}}$ (not containing Triton); (a) SEM showing the 2 regions where EDS is done, (b) EDS of region 1 and (c) EDS of region 2. 

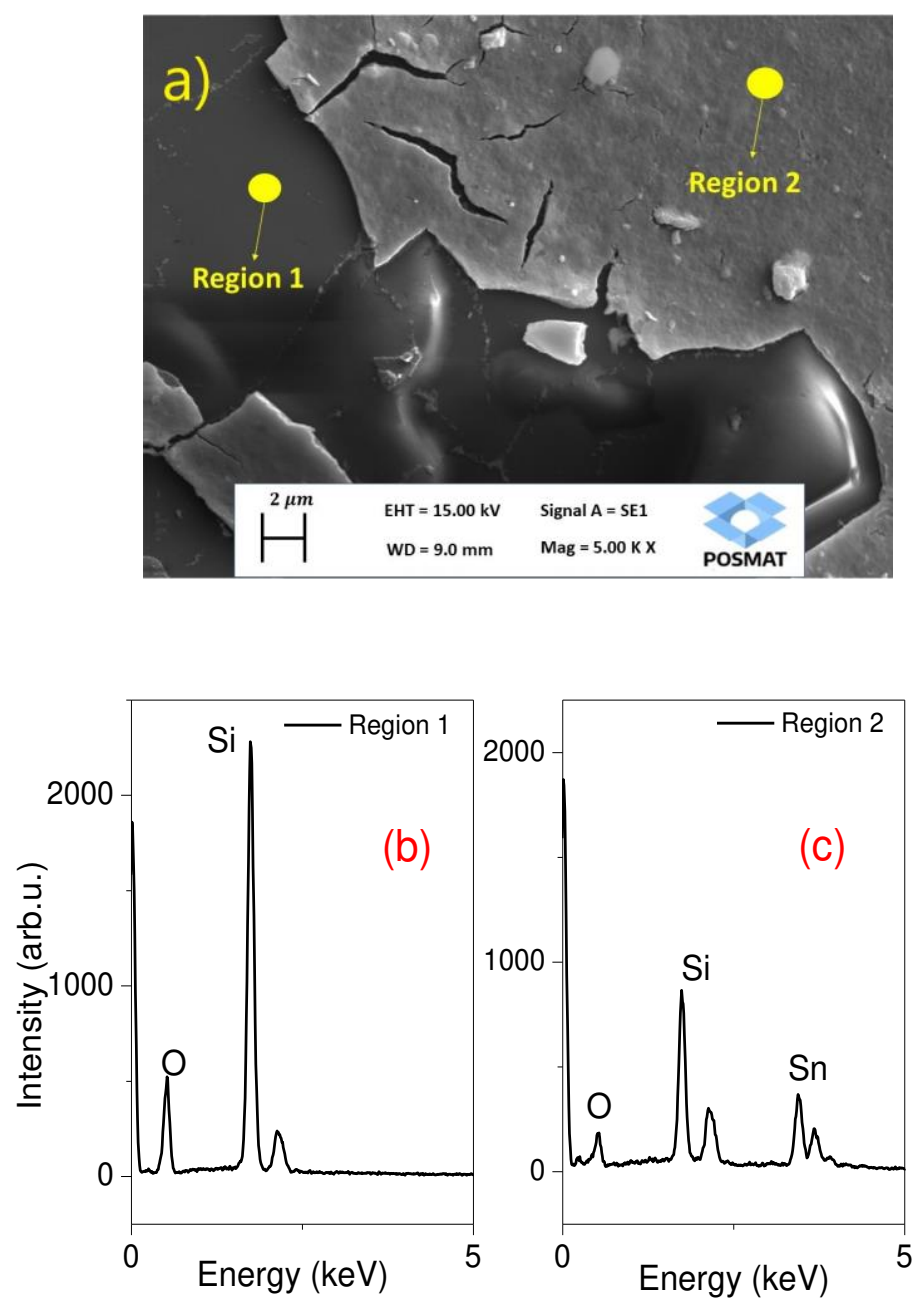

Figure 6: SEM and energy dispersive spectroscopy (EDS) of sample $S_{\mathrm{WT}}$ (containing Triton); (a) SEM showing the 2 regions where EDS is done, (b) EDS of region 1 and (c) EDS of region 2 .

As it can be observed in figure 5(a), the brighter area (called region 1) presents, as can be verified through EDS in figures 5(b), defined energy peaks for Sn, while the darker region (region 2), with EDS shown in fig. 5(c), presents only energy peaks for Si and O, elements present in the composition of the glass substrate. In figure 6(a) the regions can be more easily distinguished and the region containing Sn (region 2) is more homogeneous and extends further than the observed in figure 5(a). The EDS of the area covered with film in the case of the film deposited with Triton (fig 6(c)) shows that the Sn peaks are more intense than in the case of film without Triton (fig. 5(b)), compared to the substrate Si peaks in both cases. This confirms that for sample $S_{w t}$ a more consistent film across the substrate was deposited, 
showing that, by adding the chosen non-ionic surfactant, it is possible to enhance the deposited material's adhesion to the substrate. The EDS data presented in fig. 6 denote two regions analyzed, where 6(b) refers to region 1, where it is possible to observe characteristic emissions of tin as well as oxygen, showing the presence of the material, even though the $\mathrm{Si}$ peak is much more intense. On the other hand, in 6(c) the presence of $\mathrm{Sn}$ is not observed, only silicon and oxygen, probably referring to the substrate used.

Fig.7(a) shows the X-ray diffractogram for $\mathrm{SnO}_{2}$ thin films deposited from precursor solution with and without the presence of the surfactant. As it is possible to observe, it was not possible to obtain any information about the material deposited without Triton X-100, since the diffractogram did not show any detectable and clear diffraction peaks. This probably occurs due to the low amount of material deposited on the substrate, as shown in the confocal microscopy and SEM images, and the difficulty of centralizing the X-ray beam incident on the $\mathrm{SnO}_{2}$ islands on the sample. On the other hand, when adding $1 \%$ Triton to the colloidal suspension, the X-ray diffractogram showed characteristic peaks of $\mathrm{SnO}_{2}$ with a tetragonal structure in the rutile phase, in accordance with the JCPDS 01-088-287 crystallographic file. The presence of diffraction peaks with the addition of Triton is related to improved adhesion throughout the substrate region and increased thickness.

Concerning the powder, after evaporating the solvent from the colloidal suspension, the remaining powder was macerated and thermally annealed at $450{ }^{\circ} \mathrm{C}$ by $1 \mathrm{~h}$, within an oven with heating rate of $1{ }^{\circ} \mathrm{C} / \mathrm{min}$. This powder was then submitted to X-ray diffraction analysis, to verify possible differences in the crystalline structure of the material induced by the addition of the surfactant, or even differences in the crystallite size. The X-ray diffractograms are seen in figure $7 \mathrm{~b}$ for both situations, where it is possible to observe that the addition of surfactant does not bring meaningful differences in the crystalline structure of the material, both being identified as $\mathrm{SnO}_{2}$ with tetragonal structure in the rutile phase (JCPDS 01-088-287). Besides, as it is possible to verify through the width of the diffraction peaks, there were no significant changes in the size of the crystallites with the addition of Triton. This result was already expected, since Triton is completely eliminated at temperatures above $350{ }^{\circ} \mathrm{C}$ with relatively long treatments (above 30 minutes) [35]. The average crystallite sizes for thermal annealing at different temperatures were calculated for each plane of the identified peaks, using the Scherrer equation, and are shown in Table 3. It can be clearly observed that there is no significant change up to $550^{\circ} \mathrm{C}$, being a significant change only observable for treatment at $1000^{\circ} \mathrm{C}$. 

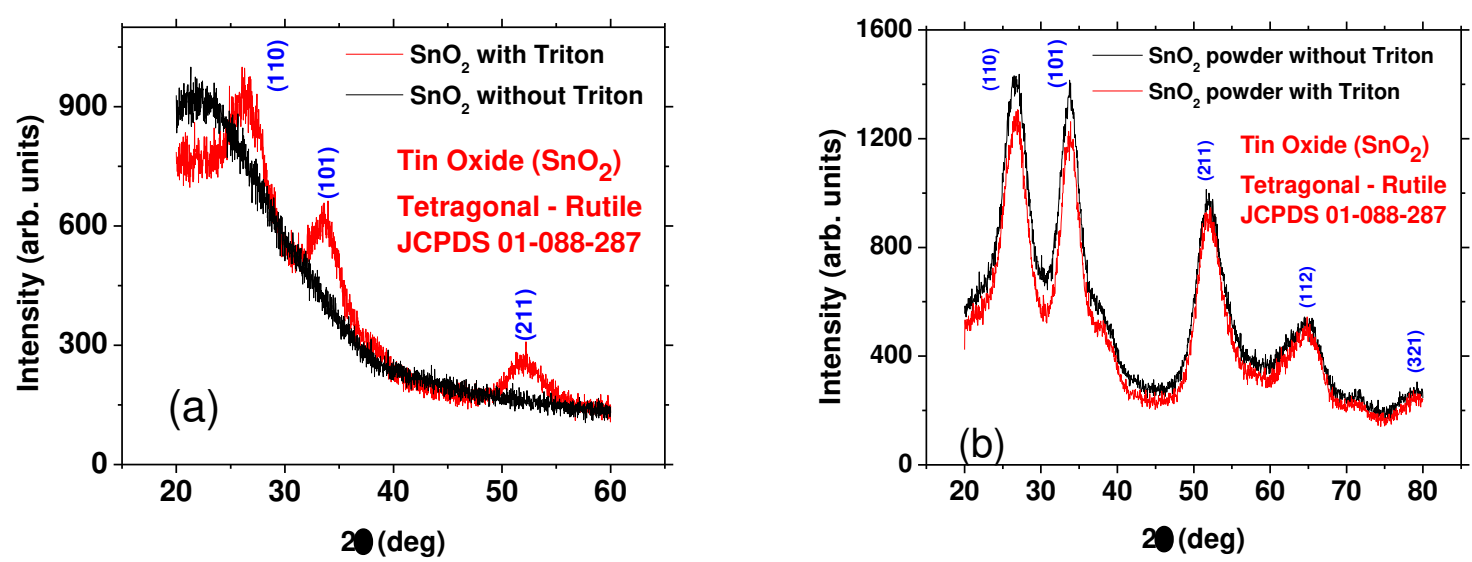

Figure 7: X-ray diffractograms for (a) $\mathrm{SnO}_{2}$ thin films, (b) powder treated at $450^{\circ} \mathrm{C}$. In both cases, data for samples obtained from solutions without and with the presence of the surfactant Triton X-100

Table 3: Average crystallite size calculated from Scherrer equation for each of the peaks identified for $\mathrm{SnO}_{2}$ powders annealed at different temperatures, obtained from colloidal suspension with and without the addition of Triton X-100.

\begin{tabular}{|cccccc|} 
Sample & $\begin{array}{c}\text { Annealing } \\
\text { temperature }\left({ }^{\circ} \mathrm{C}\right)\end{array}$ & $\begin{array}{c}\text { Plane }(110) \\
(\mathrm{nm})\end{array}$ & $\begin{array}{c}\text { Plane }(101) \\
(\mathrm{nm})\end{array}$ & $\begin{array}{c}\text { Plane }(211) \\
(\mathrm{nm})\end{array}$ & $\begin{array}{c}\text { Average } \\
(\mathrm{nm})\end{array}$ \\
\hline $\boldsymbol{S}_{\text {WT450 }}$ & 450 & 1.6 & 2.2 & 1.7 & 1.8 \\
$\boldsymbol{S}_{\text {WOT450 }}$ & 450 & 1.6 & 2.1 & 1.6 & 1.7 \\
$\boldsymbol{S}_{\text {WT550 }}$ & 550 & 2.0 & 2.9 & 2.1 & 2.3 \\
$\boldsymbol{S}_{\text {WOT550 }}$ & 550 & 1.7 & 2.6 & 1.8 & 2.0 \\
$\boldsymbol{S}_{\text {WT1000 }}$ & 1000 & 5.8 & 6.8 & 6.8 & 6.5 \\
$\boldsymbol{S}_{\text {WоT1000 }}$ & 1000 & 5.3 & 6.3 & 6.3 & 6.0
\end{tabular}

Table 3 allows observing that the difference in the size of crystallites for the powders obtained from the solutions with and without surfactant is small enough to consider that crystallites do not undergo significant changes in different samples, with and without the surfactant. With thermal annealing performed at $1000{ }^{\circ} \mathrm{C}$ the largest difference is observed, being of $0.5 \mathrm{~nm}$, showing that even with the addition of Triton X100 the structural properties are approximately the same as without the surfactant. Unfortunately, films deposited from the colloidal suspension without triton does not allow evaluating the crystallite size. However, 
through the diffractograms shown in figure 7, the estimated crystallite sizes are 2.4, 2.8 and $2.3 \mathrm{~nm}$ for the peaks associated with the planes (110), (101) and (211), respectively. It evidences the influence of the surfactant on the structural properties, since for the sample deposited from the suspension without surfactant, the diffraction peaks were not detected, showing a much less homogeneous sample and quite amorphous.

\subsection{Optical characterization}

Transmittance $(\mathrm{T})$ and reflectance $(\mathrm{R})$ spectra for a film deposited on silica substrate from a precursor solution containing triton (sample $S_{W T}$ ), are shown in figure 8(a). Film exhibits high transparency and low reflectance for visible-NIR region. The formation of interference fringes is not observed, probably due to a lack in homogeneity on the topography of surface and at the film/substrate interface for the phenomenon to occur, as the high roughness and possibly high porosity inhibits the appearance of fringes. With the values of $\mathrm{R}$ and $\mathrm{T}$ it was possible to calculate the optical absorption coefficient according to equation (1), and thus estimate the value of the indirect bandgap through the Tauc plot (Fig. 8(b)), obtaining the value of $3.7 \mathrm{eV}$, in good agreement with the literature [37-38].

Taking into account the transmittance obtained for the sample containing the surfactant, it was possible to calculate the Urbach energy using equation (2), yielding the value of $263 \mathrm{meV}$. Studies point that for polycrystalline tin dioxide in a temperature range of 340 to $360 \mathrm{~K}$, the Urbach energy ranges from 200 to $250 \mathrm{meV}[30,39,40]$. We believe that our value is close enough to the found in the literature, when taking into account that the deposition method is not the same.

The Urbach energy of the film obtained with the addition of Triton indicates the high polycrystallinity of the film, that is, with a high density of grain boundaries. It leads to a high electron scattering rate, and a high resistivity, which is temperature dependent. Besides, when the material is analyzed as function of temperature the free carrier statistics is highly dependent on the electron trapping at grain boundaries and ionized intrabandgap energy defects, suggesting high activation energy, as will be shown. 

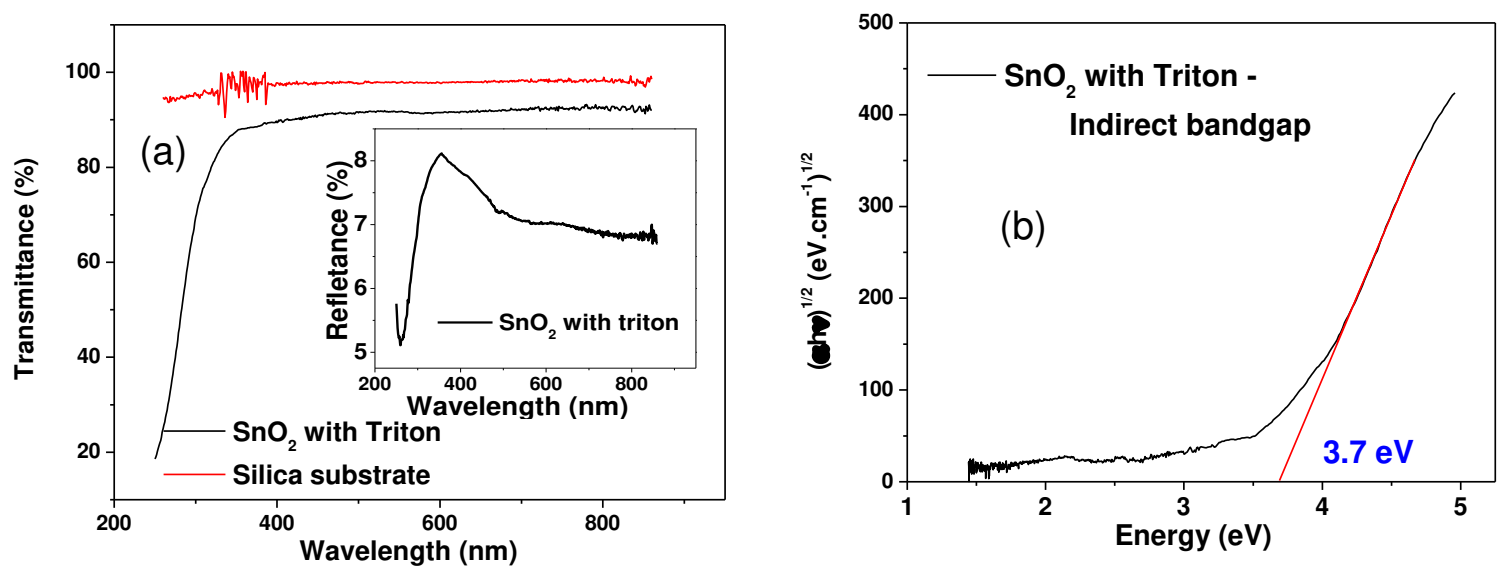

Figure 8: (a) Transmittance of $\mathrm{SnO}_{2}$ thin film deposited on silica. Inset: reflectance. (b) Tauc plot for evaluation of indirect bandgap.

\subsection{Electrical characterization}

The temperature dependent electrical behavior of the $\mathrm{SnO}_{2}$ films was evaluated through measurement of electrical current for $S_{W T}$ and $S_{W O T}$ films with a fixed applied voltage of $20 \mathrm{~V}$. Based on these data and the sample dimensions (table 1), the resistivity was evaluated and it is shown in figure 9. The inset in figure 9 is the evaluation of the main activation energy in each case, for the higher temperature range

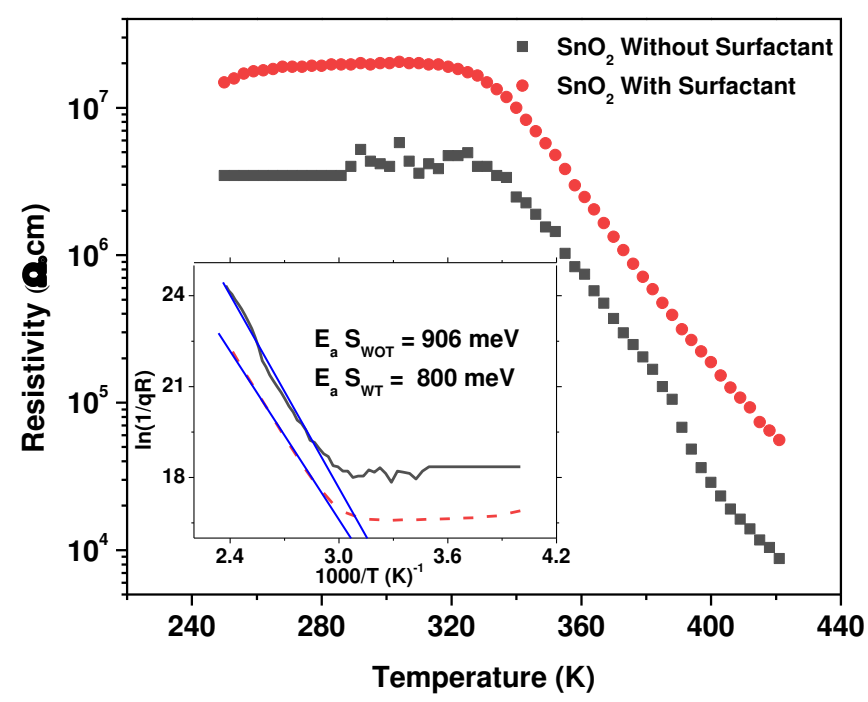

Figure 9: Resistivity as function of temperature for films deposited with and without the use of surfactant in the colloidal suspension. Inset: Arrhenius plot for determination of the main activation energy 
It is interesting to note the typical behavior of a semiconductor material for both samples in fig. 9, that is, the resistivity decreasing with the temperature rise, which becomes more pronounced after $360 \mathrm{~K}$, where the electrons trapped in the defects have sufficient thermal energy so that they can be excited to the conduction band. Overall, the resistivity of the film deposited from the colloidal suspension containing Triton is higher. This is expected, due to the higher electron scattering caused by the porosity of this sample. The drastic drop in the resistivity of $\mathrm{SnO}_{2}$ as the temperature is increased may also be related to the removal of water and $\mathrm{O}_{2}$ ionic species (at approximately $80{ }^{\circ} \mathrm{C}$ [41]) from the film surface. When the temperature required for this removal is reached, both samples behave in a similar way, differing slightly in the excitation rate, as can be seen from the inset of figure 9.

Using data of current as function of temperature, it was possible to determine the main activation energy of both films deposited with and without surfactant. The inset of figure 9 brings the Arrhenius plot from the electrical current data, leading to a behavior typical of multi-level ionized defects [42], characteristic of the continuous variation of the curve slope. This Arrhenius plot allows evaluating the activation energy for the deepest energy level, ionized at higher temperature range, which is above $360 \mathrm{~K}\left(1000 / \mathrm{T}\right.$ about $\left.2.7 \mathrm{~K}^{-1}\right)$. The addition of surfactant to the colloidal suspension of $\mathrm{SnO}_{2}$ decreases the activation energy for the deepest defect level, being $800 \mathrm{meV}$ for the film with Triton and $906 \mathrm{meV}$ without Triton, which may be an indication that the deeper intrabandgap state requires slightly less energy to be ionized, a phenomenon that may be related to the increase in the density of defects present in the sample obtained by the solution containing the Triton X-100. It is interesting to note the similarity of these values with the grain boundary potential barrier [43], obtained for samples deposited under similar conditions, which evidences the great predominance of electron scattering at the grain boundary for these films, that contain very small nanocrystallites, as shown in table 3.

\subsection{Application to Photocatalysis}

Photocatalysis measurements were performed on films obtained from colloidal suspension with and without the addition of the surfactant Triton, which were cut from the whole sample. Figure 10(a) shows the methylene blue (MB) transmittance spectra that were used as the parameter to evaluate the progress in the photocatalysis process, while the image 
in figure 10 (b) refers to the calculation of the transmittance variation by squared centimeter, in order to analyze how much of the solution has been degraded in relation to the sample dimensions.
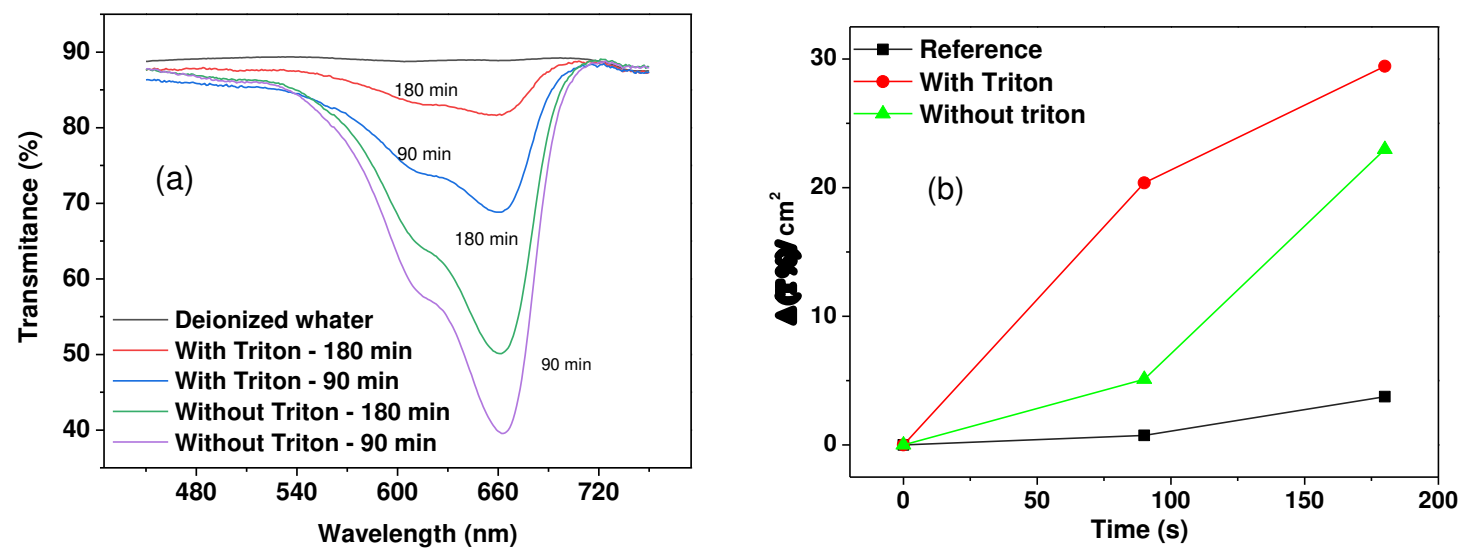

Figure 10: (a) transmittance at different degradation times of methylene blue for $\mathrm{SnO}_{2}$ films with and without surfactant (b) transmittance normalized by the surface dimensions at different degradation times of methylne blue

The transmittance data shown in figure 10(a) indicate a higher MB degradation for the thin film from the solution with surfactant, either at $90 \mathrm{~min}$ as at $180 \mathrm{~min}$. Then, lower transmittance data were observed for the film deposited without the presence of surfactant in the colloidal suspension, maintaining the same experimental conditions. The reason for this behavior is related to the increase in the surface area for the $\mathrm{SnO}_{2}$ thin films deposited from the solution with surfactant. We recall that there are two factors that influence this increase: 1) the use of the surfactant causes more pores to show up on the surface, thus increasing the contact area in relation to the films that do not contain the surfactant in its preparation [9], which has already been confirmed through confocal microscopy images, which denoted a significant increase in film roughness; 2) The second factor that could lead to the obtained results concerns the surface dimensions of the thin films deposited, as inferred from SEM images (figure 4) since the sample deposited from the solution with Triton has much larger deposited areas, caused by better adhesion, and leading the photocatalytic capacity to be affected due to these effects generated by the addition of the surfactant.

To make the comparison on the photocatalytic activity of these samples more effective, transmittance variation by unit area is plotted, as observed in figure 10(b). After 90 min a higher photocatalytic activity is observed for $S_{W T}$, denoted by a more pronounced variation in transmittance, whereas for $S_{\text {WOT }}$ no significant changes were observed. During the next $90 \mathrm{~min}$, totaling $180 \mathrm{~min}$ of experiment, the variation increased with a lower rate for 
$\mathrm{S}_{\mathrm{WT}}$, whereas for $\mathrm{S}_{\mathrm{WOT}}$ it takes place with increased rate. This phenomenon can be explained by the increased reactivity of the semiconductor oxide surface with the addition of the surfactant, since in the first $90 \mathrm{~min}$ the photocatalytic activity was greater for $S_{W T}$, but after the first 90 min there was no longer a high concentration of available $\mathrm{OH}^{-}$ions to degrade the MB solution. Different behavior occurs with $S_{W O T}$, obtained without the presence of the surfactant, which does to not have great reactivity in the first stage of the photocatalysis process, and no marked variations on the transmittance were observed. Only at the second stage the degradation rate increases significantly. The overall result, after $180 \mathrm{~min}$ of MB degradation process for both samples, is a higher reactivity for the sample obtained with the surfactant, which highlights its effectiveness on tin dioxide processing for photocatalytic applications.

\section{Conclusions}

The use of the Triton X-100 non-ionic surfactant plays a fundamental role in the fixation of the $\mathrm{SnO}_{2}$ film on soda-lime glass substrate, as evidenced by images produced through confocal and electron scanning microscopy. The surfactant's influence can also be observed in energy dispersive X-ray spectroscopy and XRD profiles, in the former case with a higher degree of crystallinity for Triton deposited films, with clear peaks of (110), (101) and (211) planes of the rutile structure. On the other hand, films obtained without the surfactant are mostly amorphous. Films present good transparency to allow for applications in transparent devices. The Tauc plot yields an average value of $3.7 \mathrm{eV}$ for indirect bandgap transition.

The introduction of this surfactant also increases the resistivity of $\mathrm{SnO}_{2}$, caused by the increase in the defect density and also in the surface area, which increases the electron scattering in the naturally n-type tin dioxide. Moreover, the addition of surfactant to the colloidal suspension decreases the activation energy for the defect with the deepest intrabanbgap energy level in the film.

Photocatalysis measurements revealed an increase in the performance when comparing films prepared without and with Triton X-100 non-ionic surfactant. From the performed experiments' data, it can be observed that most of the dye is degraded in the first 
90 minutes when interacting with the sample prepared with Triton X-100. This was related to the increase in surface area and formation of pores, which were not observed in the sample not containing surfactant.

\section{Acknowledgements:}

We thank CNPq and FAPESP (processes 2018/26039-4, 2018/25241-4 and 2019/00683-7) for financial help. We also thank Prof. Fenelon M. L. Pontes for X-ray diffraction data (CEPID/CDMF/Proc. FAPESP No 2013/07296-2)

\section{References}

[1] Batzill M, Diebold U. The surface and materials science of tin oxide. Prog Surf Sci 2005, 79: 47-154.

[2] Rai R, Senguttuvan T, Lakshmikumar S. Study of the electronic and optical bonding properties of doped $\mathrm{SnO}_{2}$. Comp Mater Sci 2006, 37: 15-19.

[3] Xu C, Jiang Y, Yi D, Sun S, Yu Z. Environment-dependent surface structures and stabilities of $\mathrm{SnO}_{2}$ from the first principles. J App. Phys 2012, 111: 063504.

[4] Geraldo V, Scalvi LV, Lisboa-Filho PN, Morilla-Santos C. Drude's model calculation rule on electrical transport in Sb-doped $\mathrm{SnO}_{2}$ thin films, deposited via sol-gel. J Phys Chem Solids 2006, 67: 1410-1415.

[5] Tsunashima A, Yoshimizu H, Kodaira K, Shimada S, Matsushita T. Preparation and properties of antimony-doped $\mathrm{SnO}_{2}$ films by thermal decomposition of tin 2ethylhexanoate. J Mater Sci. 1986, 21: 2731-2734.

[6] Gonzalez-Oliver C, Kato I. Sn (Sb)-oxide sol-gel coatings on glass. J Non-Cryst. Solids 1986, 82: 400-410.

[7] Takahashi Y, Wada Y. Dip-coating of Sb-doped $\mathrm{SnO}_{2}$ films by ethanolamine-alkoxide method. J Electrochem Soc 1990, 137: 267.

[8] Afzal M, Naik P, Nadaf L, Shaikh IN. SnO 2 -Surfactant Composite Films for Superior Gas 
Sensitivity. SSRG International Journal Of Applied Physics (SSRG-IJAP) 2016, 3: 1-5.

[9] Bhattacharjee A, Ahmaruzzaman M, Sinha T. Surfactant effects on the synthesis of durable tin-oxide nanoparticles and its exploitation as a recyclable catalyst for the elimination of toxic dye: a green and efficient approach for wastewater treatment. RSC Advances 2014, 4: 51418-51429.

[10] Rac O, Suchorska-Wozniak P, Fiedot M, Teterycz H, Influence of stabilizing agents and pH on the size of $\mathrm{SnO}_{2}$ nanoparticles. Beilstein J. Nanotech 2014, 5: 2192-2201.

[11] Yang G, Yan Z, Xiao T. Preparation and characterization of $\mathrm{SnO}_{2} / \mathrm{ZnO} / \mathrm{TiO}_{2}$ co posite semiconductor with enhanced photocatalytic activity. Appl Surf Sci 2012, 258: 87048712.

[12] Zhang L, Yu W, Han C, Guo J, Zhang Q, Xie H, et al. Large scaled synthesis of heterostruc- tured electrospun $\mathrm{TiO}_{2} / \mathrm{SnO}_{2}$ nanofibers with an enhanced photocatalytic activity. J Electrochem Soc 2017 164: H651.

[13] Niu M, Huang F, Cui L, Huang P, Yu Y, Wang Y. Hydrothermal synthesis, structural characteristics, and enhanced photocatalysis of $\mathrm{SnO}_{2} / \alpha-\mathrm{Fe}_{2} \mathrm{O}_{3}$ semiconductor nanoheterostructures. ACS Nano 2010, 4: 681-688.

[14] Hou LR, Yuan CZ, Peng Y. Synthesis and photocatalytic property of $\mathrm{SnO}_{2} / \mathrm{TiO}_{2}$ nanotubes composites. J Hazardous Mater 2007, 139: 310-315.

[15] Ding K, Miao Z, Hu B, An G, Sun Z, Han B, et al. Study on the anatase to rutile phase transformation and controlled synthesis of rutile nanocrystals with the assistance of ionic liquid. Langmuir 2010, 26: 10294-10302.

[16] Jean J, Ring T. Nucleation and growth of monosized titania powders from alcohol solution. Langmuir 1986, 2: 251-255.

[17] Dong J, Chen S, Corti DS, Franses EI, Zhao Y, Ng HT, et al. Effect of Triton X-100 on the stability of aqueous dispersions of copper phthalocyanine pigment nanoparticles. $J$. Colloid Interf. Sci. 2011, 362: 33-41

[18] Hidalgo D, Messina R, Sacco A, Manfredi D, Vankova S, Garrone E, et al. Thick mesoporous $\mathrm{TiO}_{2}$ films through a sol-gel method involving a non-ionic surfactant: Characterization and enhanced performance for water photo-electrolysis. Int $J$ Hydrogen Energ 2014, 39: 21512-21522. 
[19] Yang YJ, Corti DS, Franses EI. Effect of Triton X-100 on the stability of titania nanoparticles against agglomeration and sedimentation: a masked depletion interaction. Colloid Surface A 2017, 516: 296-304.

[20] Aziz MHA, Sauli Z, Retnasamy V, Wan Norhaimi WM, Taniselass S, Kamarudin H. Contact Angle Analysis on Glass Based Surface. In:Applied Mechanics And Materials, Vol. 680, Trans Tech Publ, 2014. p. 93-96.

[21] Ravaro LP, Scalvi LV, Tabata AS, Pontes FM, Oliveira JB. Nanoparticle characterization of Er-doped $\mathrm{SnO}_{2}$ pellets obtained with different $\mathrm{pH}$ of colloidal suspension. $J$ Appl Phys 2013, 114: 084304

[22] Aziz M, Abbas SS, Baharom WRW, Mahmud WZW. Structure of $\mathrm{SnO}_{2}$ nanoparticles by sol-gel method. Mater Lett 2012, 74: 62-64.

[23] Tauc J. Optical properties and electronic structure of amorphous Ge and Si. Mater Res Bull 1968, 3: 37-46.

[24] Çetinörgü E, Goldsmith S, Boxman R. Air annealing effects on the optical properties of $\mathrm{ZnO}-\mathrm{SnO}_{2}$ thin films deposited by a filtered vacuum arc deposition system. Semicond Sci Tech 2006, 21: 364.

[25] Robertson J. Electronic structure of $\mathrm{SnO}_{2}, \mathrm{GeO}_{2}, \mathrm{PbO}_{2}, \mathrm{TeO}_{2}$ and $\mathrm{MgF}_{2}$. J Phys C: Solid State Phys 1979, 12: 4767.

[26] Mulvaney P, Grieser F, Meisel D. Electron transfer in aqueous colloidal tin dioxide solutions. Langmuir 1990, 6: 567-572.

[27] Gu Z, Liang P, Liu X, Zhang W, Le Y.Characteristics of sol-gel $\mathrm{SnO}_{2}$ films treated by ammonia. J Sol-Gel Sci Technol 2000, 18:159-166.

[28] Pineiz TF, De Morais EA, Scalvi LV, Bueno CF. Interface formation of nanostructured heterojunction $\mathrm{SnO}_{2}: \mathrm{Eu} / \mathrm{GaAs}$ and electronic transport properties Appl. Surf. Sci. 2013, 267: 200-205.

[29] Zanatta A. Revisiting the optical bandgap of semiconductors and the proposal of a unified methodology to its determination. Sci Rep-UK 2019, 9: 1-12.

[30] Ikhmayies SJ, Ahmad-Bitar RN. An investigation of the bandgap and Urbach tail of vacuum-evaporated $\mathrm{SnO}_{2}$ thin films. Renew Energ 2013, 49: 143-146. 
[31] Libanori R, Giraldi TR, Longo E, Leite ER, Ribeiro C. Effect of TiO 2 surface modification in Rhodamine B photodegradation. J Sol-Gel Sci Technol 2009, 49: 95-100.

[32] Chen X, Mao SS. Titanium dioxide nanomaterials: synthesis, properties, modifications, and applications. Chem Rev 2007, 107: 2891-2959.

[33] Hou SX. Adsorption properties of pomelo peels against methylene blue in dye wastewater. In Advanced Materials Research, Vol. 634, Trans Tech Publ, 2013, 178181.

[34] Dinh VP, Le HM, Nguyen VD, Dao VA, Hung NQ, Tuyen LA, et al. Insight into the adsorption mechanisms of methylene blue and chromium (III) from aqueous solution onto pomelo fruit peel. RSC Advances 2019, 9: 25847-25860.

[35] Casali RA, Lasave J, Caravaca M, Koval S, Ponce C, Migoni RL. Ab initio and shell model studies of structural, thermoelastic and vibrational properties of $\mathrm{SnO}_{2}$ under pressure. J Phys-Condens Mat 2013, 25: 135404.

[36] Ghaemi M, Ghafouri E, Neshati J. Influence of the nonionic surfactant Triton X-100 on electrocrystallization and electrochemical performance of lead dioxide electrode. $J$ Power Sources, 2006, 157: 550-562.

[37] Schipani F, Ponce MA, Joanni E, Williams FJ, Aldao CM. Study of the oxygen vacancies changes in $\mathrm{SnO}_{2}$ polycrystalline thick films using impedance and photoemission spectro- scopies. J Appl Phys 2014, 116: 194502.

[38] Yamazoe N, Fuchigami J, Kishikawa M, Seiyama T. Interactions of tin oxide surface with $\mathrm{O}_{2}, \mathrm{H}_{2} \mathrm{O}$ and $\mathrm{H}_{2}$. Surf. Sci. 1979, 86: 335-344.

[39] Melsheimer J, Ziegler D. Band gap energy and Urbach tail studies of amorphous, partially crystalline and polycrystalline tin dioxide. Thin Solid Films 1985, 129: 35-47.

[40] Ikhmayies SJ, Ahmad-Bitar RN. An investigation of the bandgap and Urbach tail of spray- deposited $\mathrm{SnO}_{2}: \mathrm{F}$ thin films. Physica Scripta, 2011, 84: 055801.

[41] Serin T, Serin N, Karadeniz S, Sari H, Tugluoglu N, Pakma O. Electrical, structural and optical properties of $\mathrm{SnO}_{2}$ thin films prepared by spray pyrolysis. J Non-Cryst Solids 2006, 352: 209-215.

[42] Ravaro LP, dos Santos DI, Scalvi LV. Effect of $\mathrm{pH}$ of colloidal suspension on crystallization and activation energy of deep levels in $\mathrm{SnO}_{2}$ thin films obtained via sol- 
gel. J Phys Chem. Solids 2009, 70: 1312-1316.

[43] Pinheiro MA, Pineiz TF, de Morais EA, Scalvi LV, Saeki MJ, Cavalheiro AA. Schottky emission in nanoscopically crystallized Ce-doped $\mathrm{SnO}_{2}$ thin films deposited by sol-geldip-coating. Thin Solid Films 2008, 517: 976-981. 
Figures

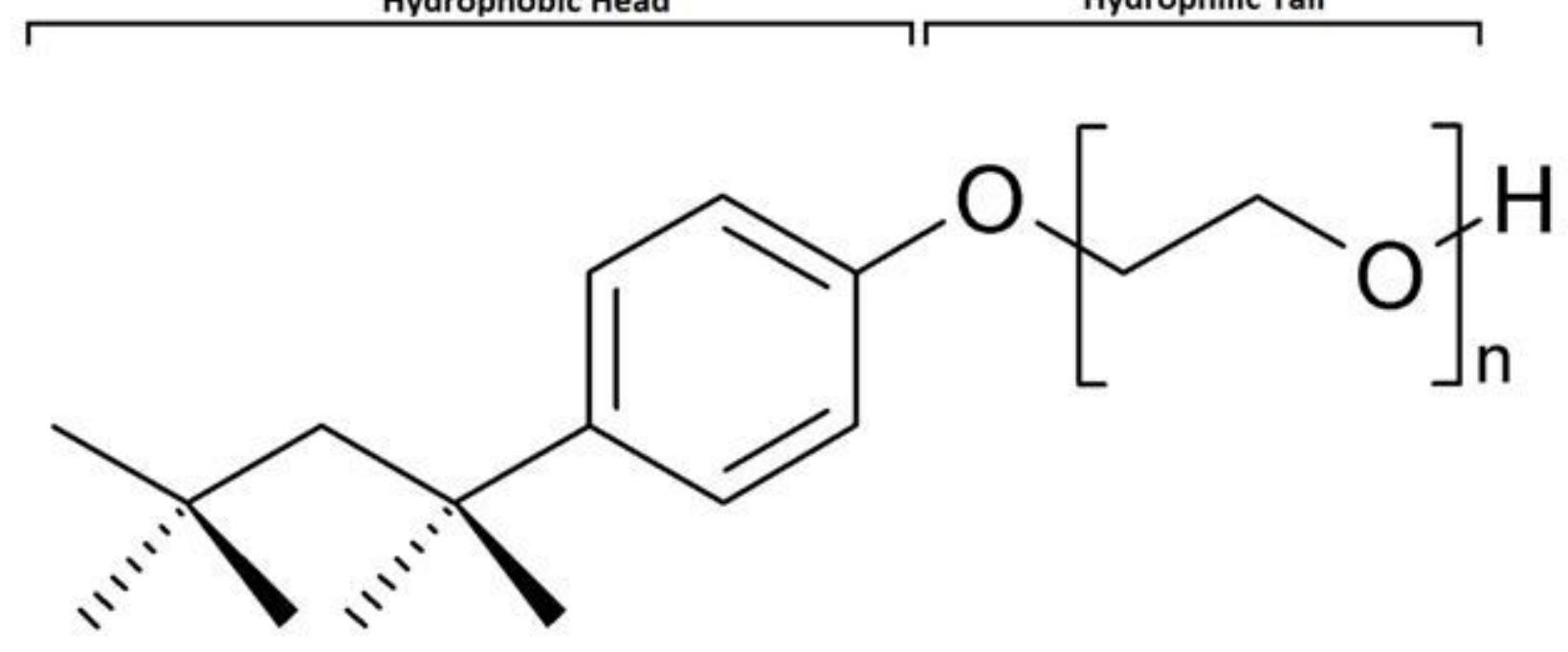

Figure 1

Triton $\mathrm{X}-100$ molecule $(\mathrm{C} 14 \mathrm{H} 22 \mathrm{O}(\mathrm{C} 2 \mathrm{H} 40) \mathrm{n})$, where $\mathrm{n}$ is between 9 or 10 unities.
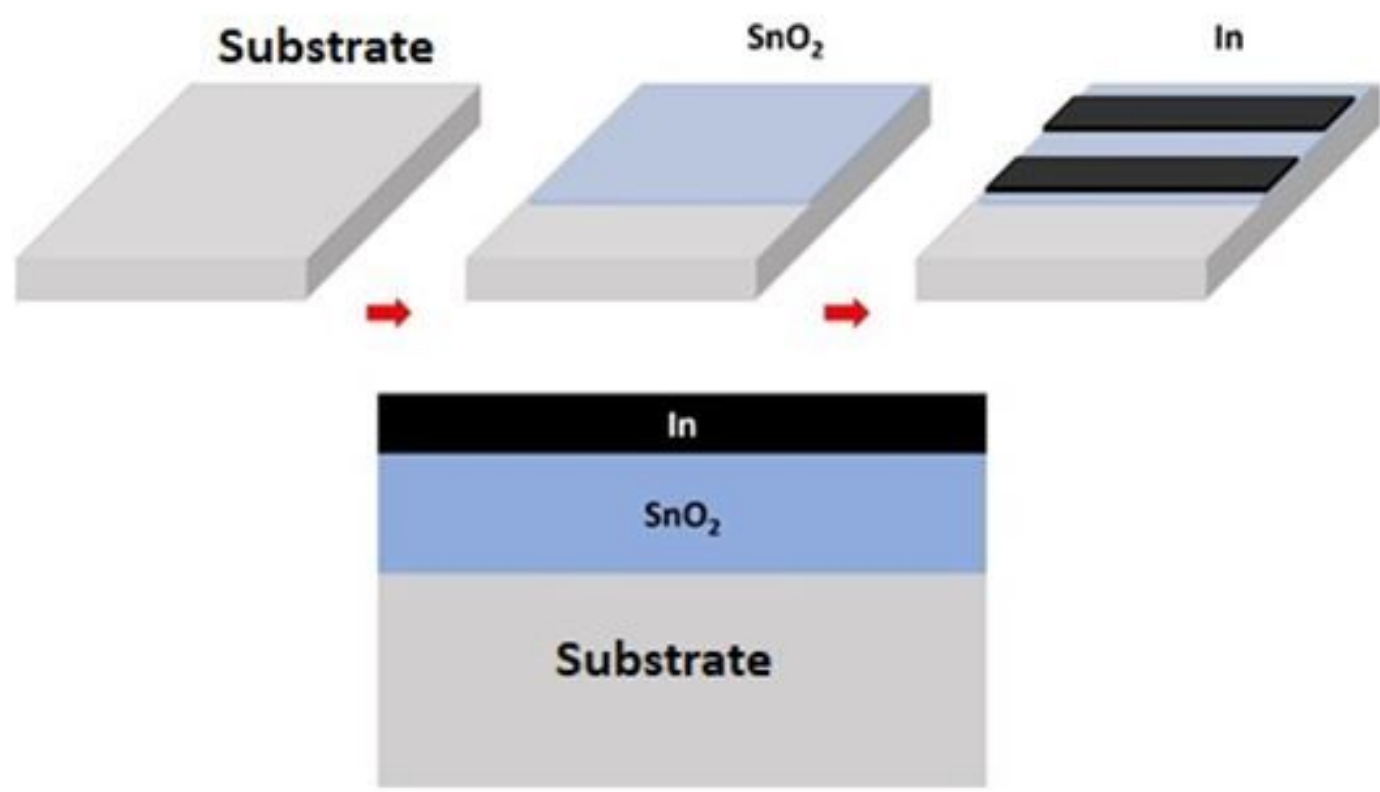

Figure 2

Diagram of SnO2 samples used in this work. Thin film deposited by sol-gel dip-coating, and metallic In contact deposited by resistive evaporation technique. 

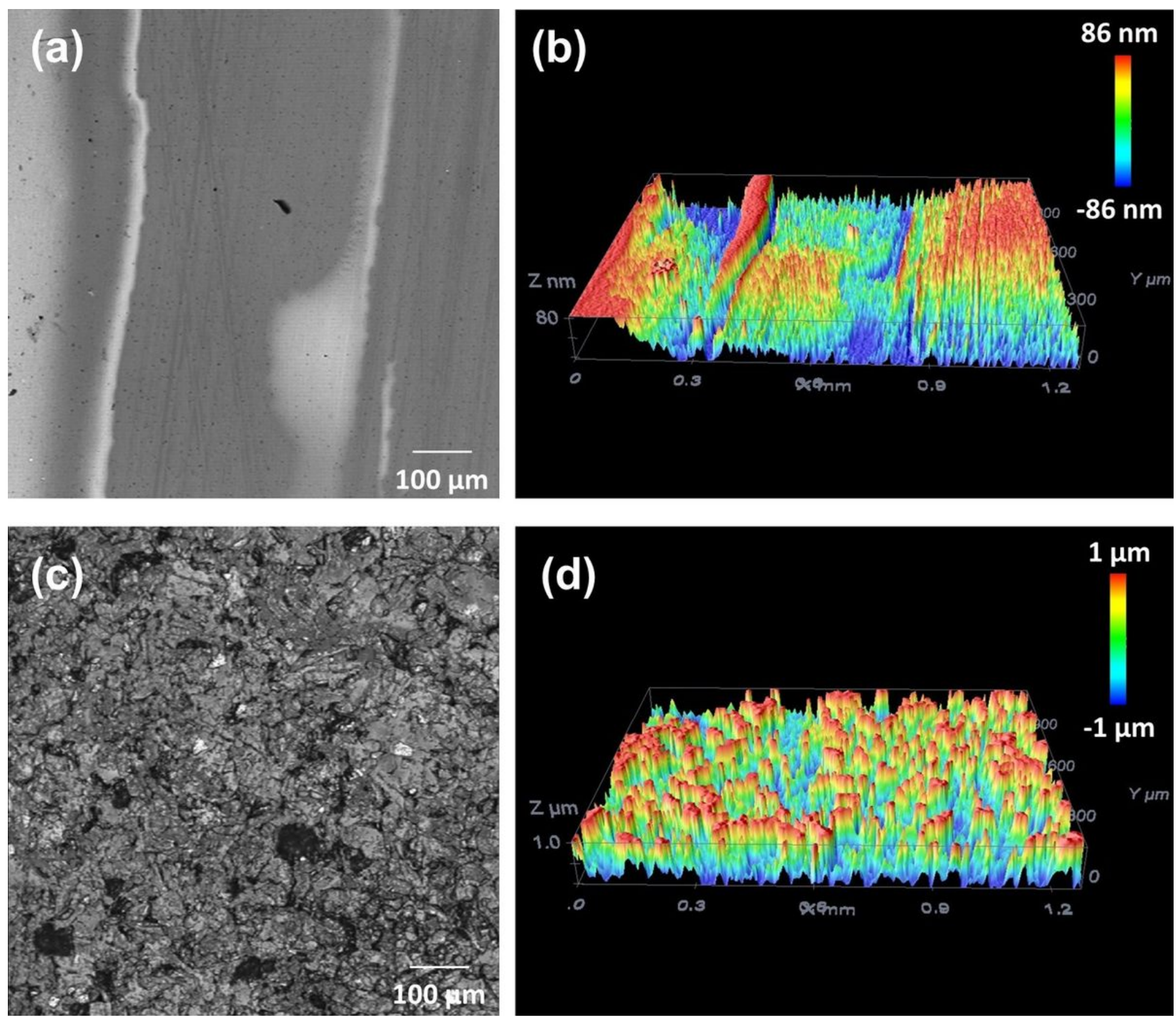

Figure 3

Confocal microscopy images of SnO2 films without Triton in (a) surface and (b) topography mode. Confocal microscopy images of SnO2 samples with Triton in (c) surface and (d) topography mode. 

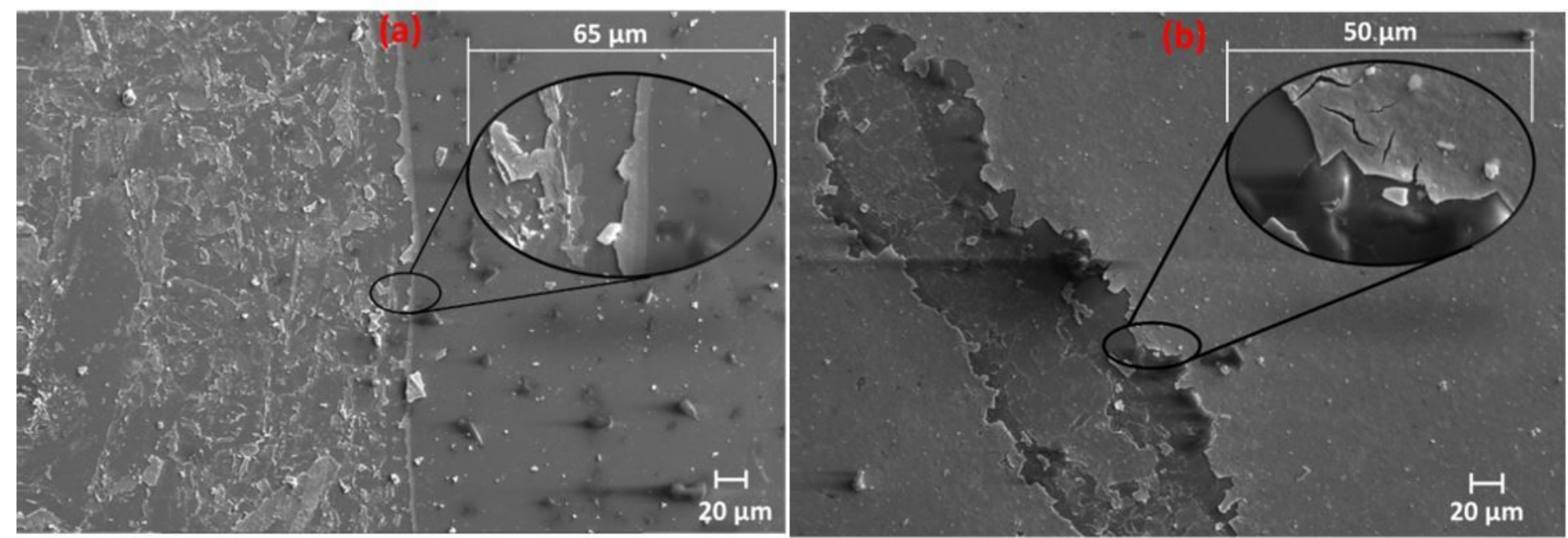

\section{Figure 4}

Scanning electron microscopy carried out with magnification 30x and scale bar of $20 \mu \mathrm{m}$ for (a) Swot film (without Triton) and (b) SWT. The insets are amplification of the highlighted region in a different magnification for better visualization. 

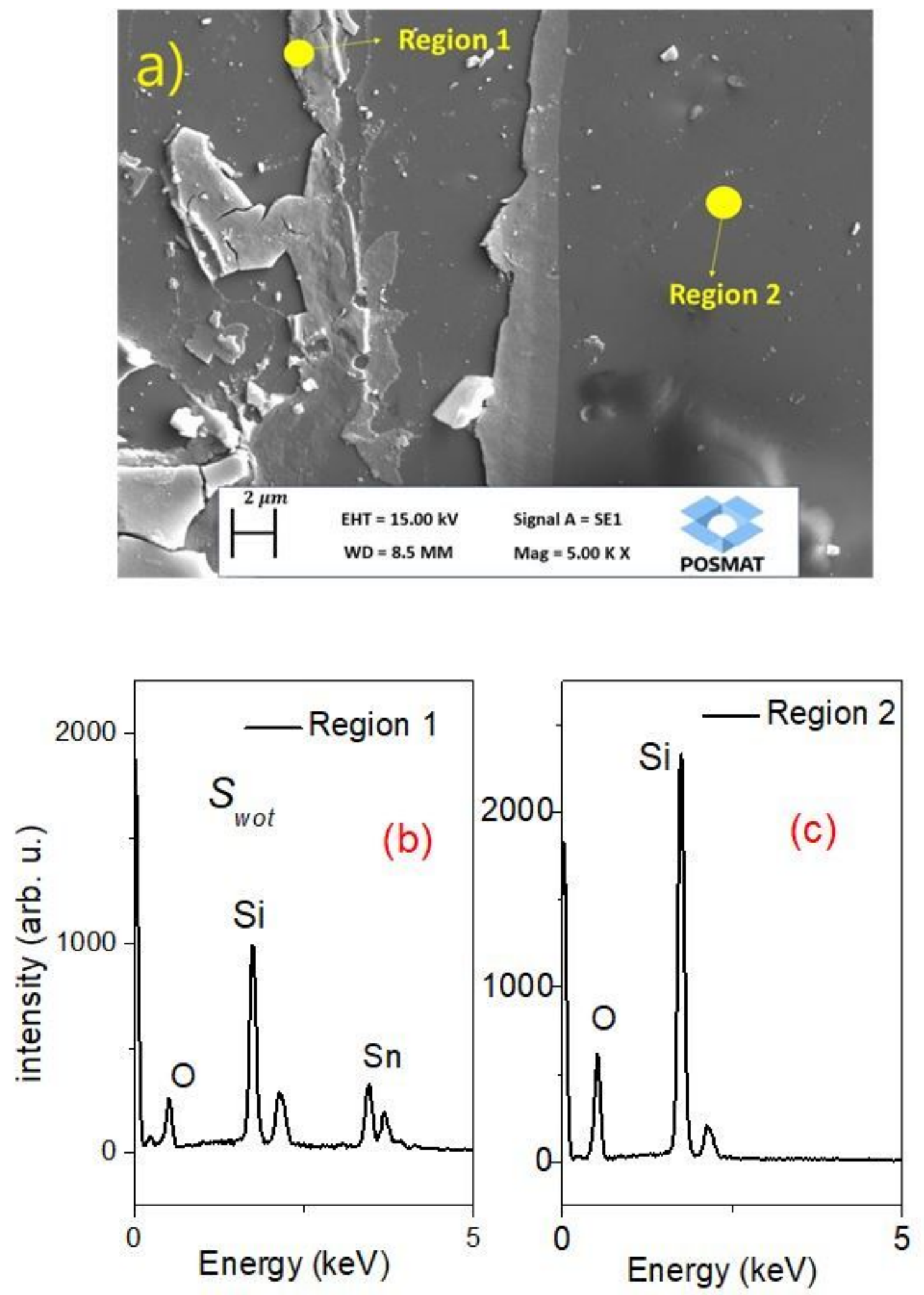

Figure 5

SEM and energy dispersive spectroscopy (EDS) of sample SWOT (not containing Triton); (a) SEM showing the 2 regions where EDS is done, (b) EDS of region 1 and (c) EDS of region 2. 

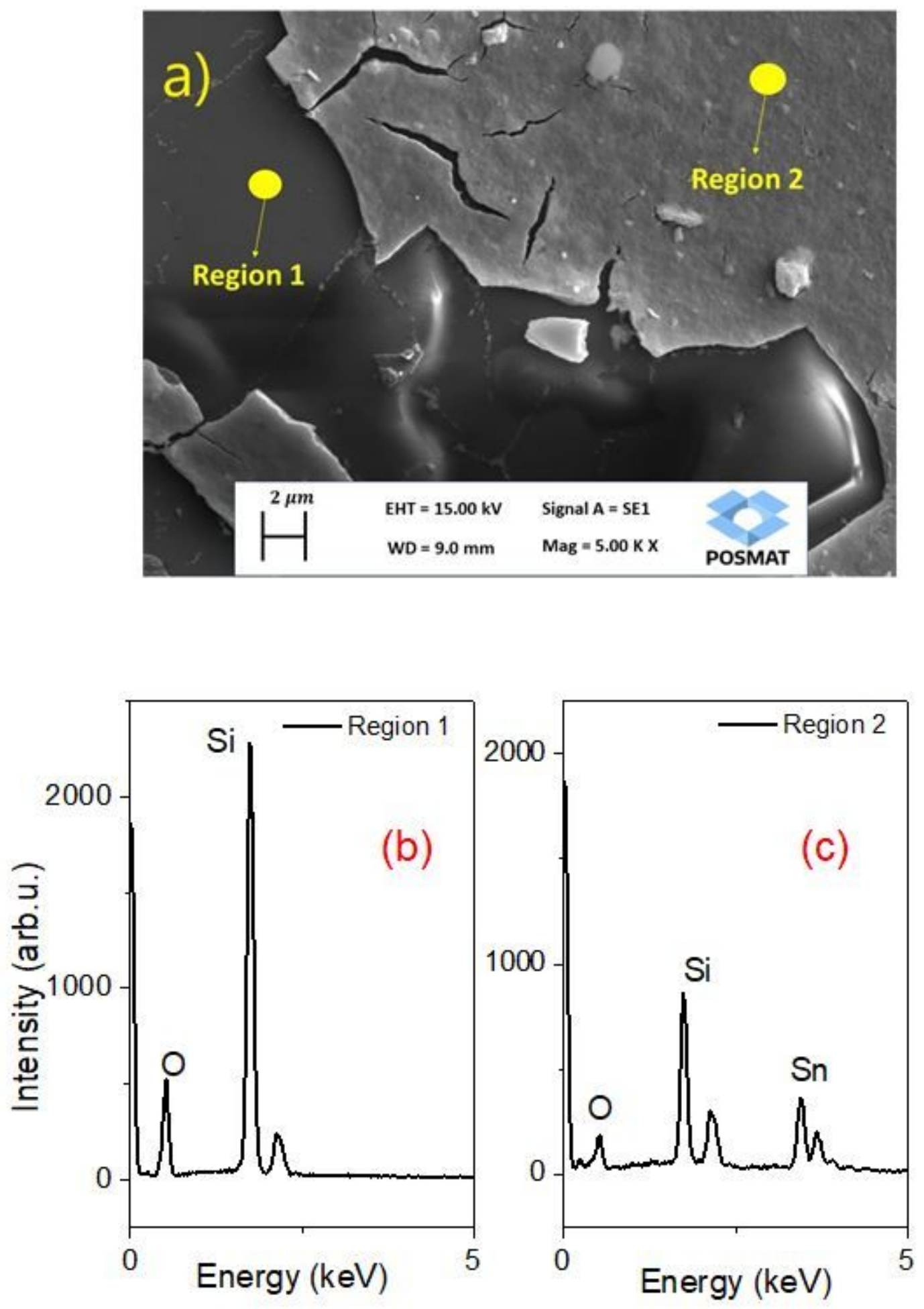

Figure 6

SEM and energy dispersive spectroscopy (EDS) of sample SWT (containing Triton); (a) SEM showing the 2 regions where EDS is done, (b) EDS of region 1 and (c) EDS of region 2. 

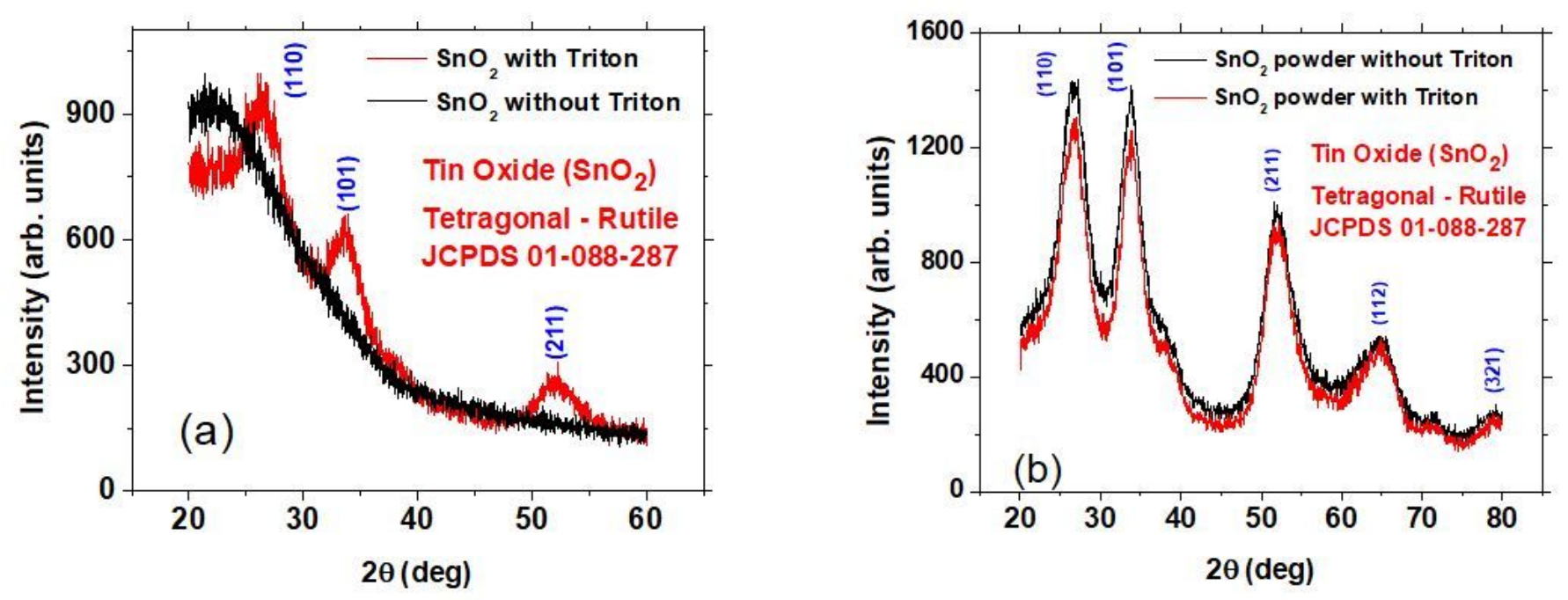

Figure 7

X-ray diffractograms for (a) SnO2 thin films, (b) powder treated at $450 \mathrm{oC}$. In both cases, data for samples obtained from solutions without and with the presence of the surfactant Triton X-100
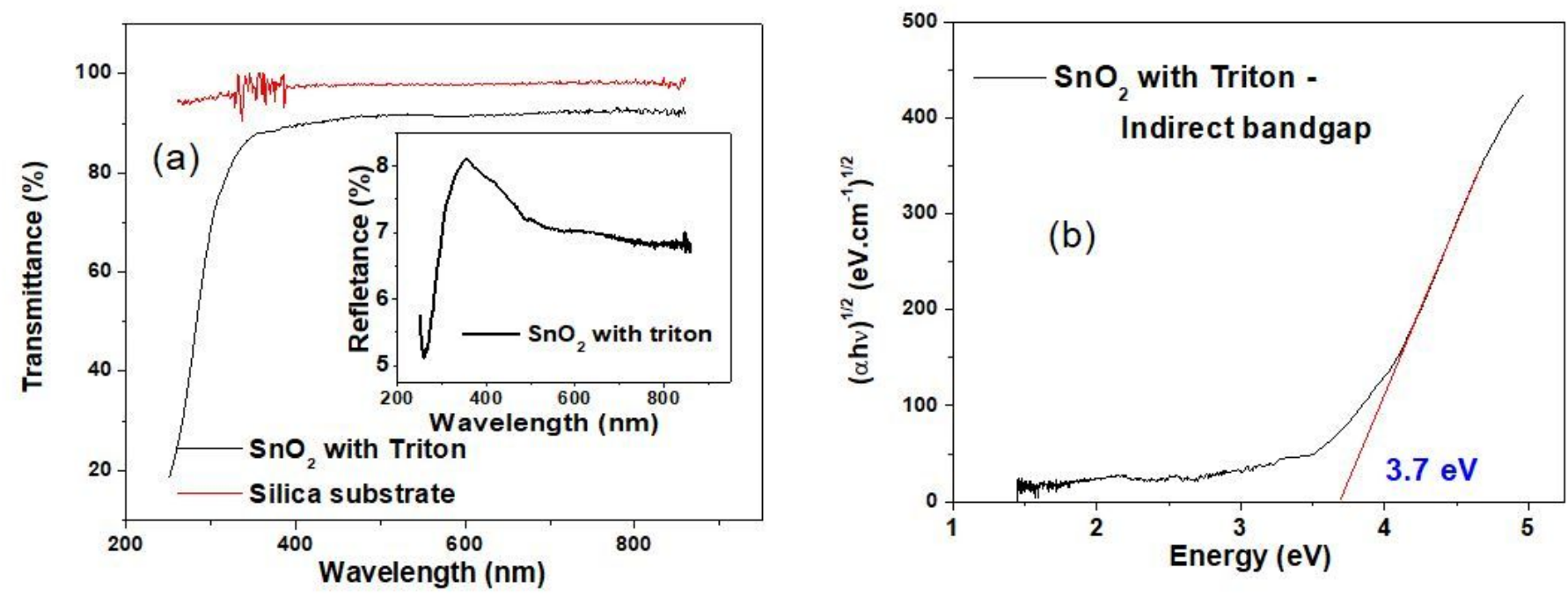

Figure 8

(a) Transmittance of SnO2 thin film deposited on silica. Inset: reflectance. (b) Tauc plot for evaluation of indirect bandgap. 


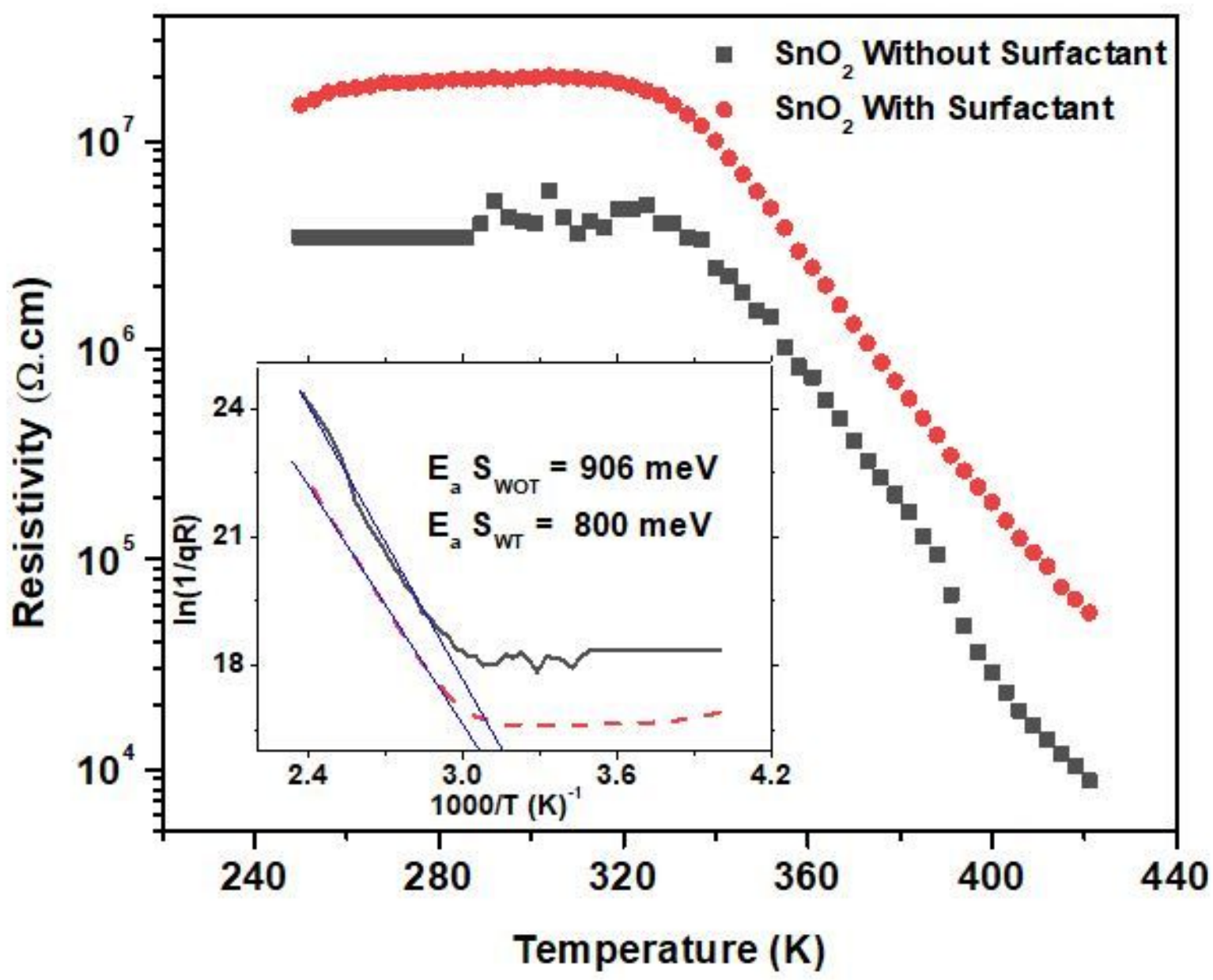

Figure 9

Resistivity as function of temperature for films deposited with and without the use of surfactant in the colloidal suspension. Inset: Arrhenius plot for determination of the main activation energy
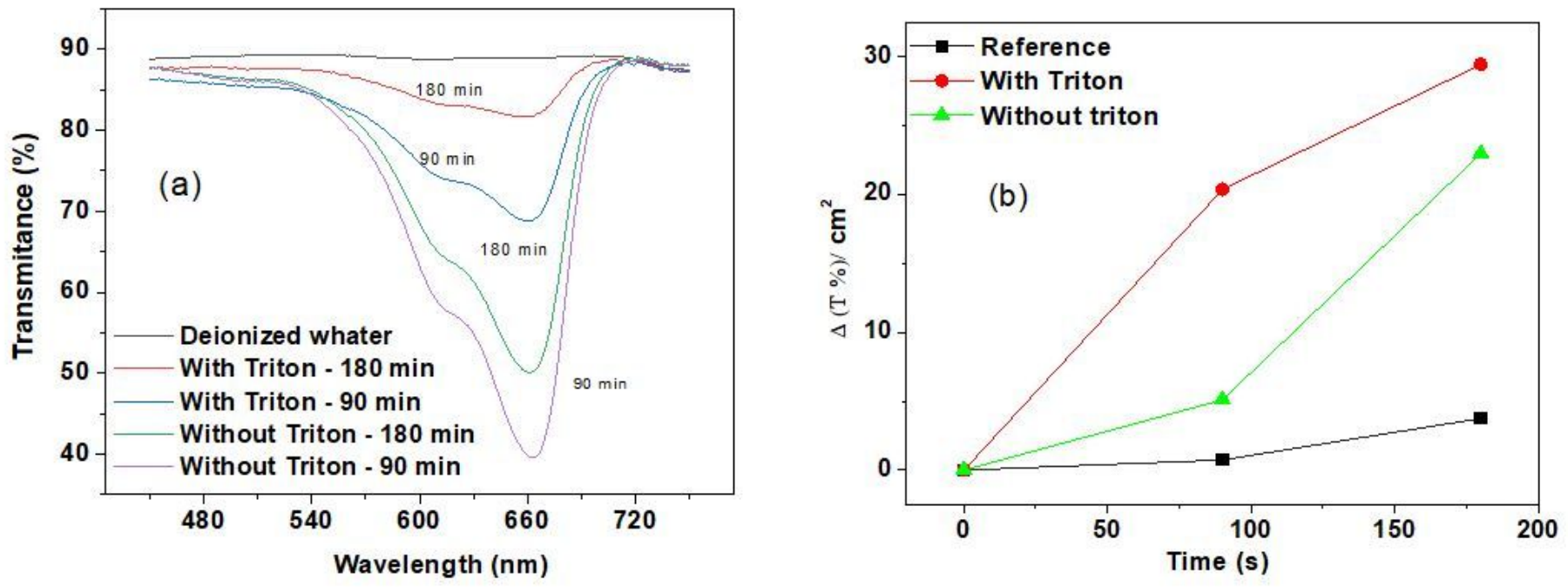

Figure 10 
(a) transmittance at different degradation times of methylene blue for SnO2 films with and without surfactant (b) transmittance normalized by the surface dimensions at different degradation times of methylne blue 